\title{
Imaging of urinary tract in children in different clinical scenarios: a guide for general radiologists
}

\author{
Shaimaa Abdelsattar Mohammad ${ }^{1 *}$ (D) Leila M. Rawash and Amr Abdelhamid AbouZeid ${ }^{2}$
}

\begin{abstract}
Background: Children are frequently referred to the pediatric radiology department due to complaints related to the urinary tract.

Main body: We aimed to describe common clinical scenarios in paediatric urology practice and their recommended imaging diagnostic algorithms. Practical imaging approach to following common clinical scenarios and the common radiological findings are discussed: (A) perinatal urinary tract dilatation and other congenital anomalies; (B) recurrent urinary tract infection; (C) enuresis and daytime urinary incontinence; (D) abdominal masses; (E) flank pain; (F) hematuria; (G) trauma; $(\mathrm{H})$ nonpalpable testis, ambiguous genitalia and common urogenital sinus anomalies; and I) renovascular hypertension
\end{abstract}

Conclusions: Imaging investigations should be tailored according to the clinical presentation in a stepwise approach aiming for optimum patients' care.

Keywords: Urinary tract dilatation, Vesicoureteric reflux, Renal masses, Renovascular hypertension, Imaging guideline, Congenital anomalies

\section{Background}

Children are frequently referred to the pediatric radiology department due to complaints related to the urinary tract. Perinatal urinary tract dilatation, recurrent urinary tract infection and enuresis are frequently encountered. Hematuria, loin pain or abdominal masses are also among the presenting symptoms of urologic diseases. Children may be referred following trauma or to investigate hypertension. Establishing diagnostic approaches and imaging protocols is of paramount importance for the evaluation and management of pediatric urinary tract disorders entailing proper selection of appropriate imaging modality for a given clinical scenario [1]. Pediatric imaging recommendations have been elaborated

\footnotetext{
*Correspondence: shaimaa96@hotmail.com

1 Department of Radiodiagnosis, Faculty of Medicine, Ain Shams

Universuty, Cairo, Egypt

Full list of author information is available at the end of the article
}

by European society of pediatric radiology Uroradiology Task Force and ESUR Paediatric Working Group [2-8]. The current review intends to outline practical imaging approach to common clinical presentations in paediatric urology practice. Common radiological findings in different scenarios are also demonstrated.

\section{Main text}

Practical imaging approach to following common clinical scenarios and the common radiological findings are discussed (Table 1): (A) perinatal urinary tract dilatation and other congenital anomalies; (B) recurrent urinary tract infection; $(C)$ enuresis and daytime urinary incontinence; (D) abdominal masses; (E) flank pain; (F) hematuria; (G) trauma; (H) nonpalpable testis, ambiguous genitalia and common urogenital sinus anomalies; and (I) renovascular hypertension. 
Table 1 Different clinical scenarios and imaging guideline

\begin{tabular}{|c|c|}
\hline Clinical scenarios & Imaging guideline \\
\hline Perinatal urinary tract dilatation & $\begin{array}{l}\text { Ultrasound } \\
\text { After sonographic detection of UTD, MCUG may be required for detection of VUR or PUV } \\
\text { If reflux is found, Tc-99m-DMSA scintigraphy is the investigation of choice for functional } \\
\text { If VUR is not encountered, so obstruction is the probable cause of UTD for dynamic renal scintigraphy } \\
\text { MRI also can be requested especially in complex renal anomalies (robust anatomical and functional capa- } \\
\text { bilities) }\end{array}$ \\
\hline Recurrent urinary tract infection & $\begin{array}{l}\text { Ultrasound in infants below two years or present with atypical or recurrent UTI } \\
\text { MCUG in all children with abnormal ultrasound or atypical or recurrent UTI } \\
\text { MCUG, and if positive, DMSA scintigraphy; Or DMSA scintigraphy and if positive MCUG }\end{array}$ \\
\hline Enuresis and daytime urinary incontinence & $\begin{array}{l}\text { Screening ultrasound (pre-void and post-void scan) } \\
\text { MRI of the spine is reserved for children with suspected abnormalities of the lumbosacral spine } \\
\text { MR urography can be of value in detection of structural anomalies particularly ectopic ureter } \\
\text { IVP may be of value if the access to MRI is limited }\end{array}$ \\
\hline Abdominal masses & $\begin{array}{l}\text { Following ultrasound, cross-sectional imaging with CT or MRI is mandatory for further evaluation and initial } \\
\text { staging } \\
\text { CT enables simultaneous evaluation of both lungs } \\
\text { MRI is more sensitive in detecting contralateral synchronous masses }\end{array}$ \\
\hline Flank pain & $\begin{array}{l}\text { Ultrasound and radiography } \\
\text { Low-dose non-contrast CT should be reserved when ultrasound is non-diagnostic or further anatomical } \\
\text { details are needed for surgical intervention }\end{array}$ \\
\hline Hematuria & $\begin{array}{l}\text { Ultrasound } \\
\text { Subsequent imaging depends on the initial ultrasound findings }\end{array}$ \\
\hline Trauma & $\begin{array}{l}\text { Ultrasound is the first modality for trauma surveillance especially in patients with minimal symptoms } \\
\text { Four-phase post-contrast CT of the urinary tract (Pre- and post-contrast phases in arterial, nephrographic } \\
\text { and pyelographic phases) }\end{array}$ \\
\hline $\begin{array}{l}\text { Nonpalpable testis, ambiguous genitalia } \\
\text { and common urogenital sinus anomalies }\end{array}$ & $\begin{array}{l}\text { General guidelines recommend against preoperative imaging of nonpalpable testis } \\
\text { Ultrasound and or MRI in cases of ambiguous genitalia } \\
\text { Genitogram represents the main preoperative radiological assessment in urogenital sinus anomalies, some } \\
\text { centres may add pelvic MRI }\end{array}$ \\
\hline Renovascular hypertension & $\begin{array}{l}\text { Ultrasound with Doppler is the initial imaging modality } \\
\text { CT or MR angiography are the recommended further imaging modalities } \\
\text { Catheter angiography after failure of medical therapy for hypertension or when ultrasound reveals size } \\
\text { discrepancy between both kidneys, or in children with neurofibromatosis }\end{array}$ \\
\hline
\end{tabular}

(A) Perinatal urinary tract dilatation and other congenital anomalies

Perinatal urinary tract dilatation (UTD) is commonly encountered among children with complaints related to urinary tract. It can be detected on antenatal screening or in the work up of children with recurrent urinary tract infection. Being available, devoid of ionizing radiation and a bed side examination tool, ultrasound is the ideal initial imaging modality. Ultrasound check list has been developed to objectively assess the urinary system in children. It comprises assessment of renal parenchymal echogenicity and thickness; presence of parenchymal cysts; determination of anteroposterior renal pelvic diameter; accurate estimation of renal calyceal dilatation (central or peripheral); assessment of the ureters (dilated, not dilated, duplication); urinary bladder wall thickness, trabeculations and diverticulae, ureterocele and if the posterior urethra is dilated [9]. In this initial examination, various urinary tract anomalies can be diagnosed guiding for further diagnostic procedures (Fig. 1). Ultrasound also enables cine display during filling and emptying of ureterocele (Additional file 1). Recently, urinary tract dilatation grading system has been developed aiming for standardization of the grading system which has important prognostic and therapeutic implications (Table 2) [9].

Semiautomatic quantification of urinary tract dilatation severity can be achieved by newly emerged two-dimensional ultrasound technologies. Size of the collecting system, depth of the calyces and renal parenchymal thickness can be calculated. These measurements are subsequently used in identifying those patients who will benefit from diuretic scintigraphy [10]. Novel 

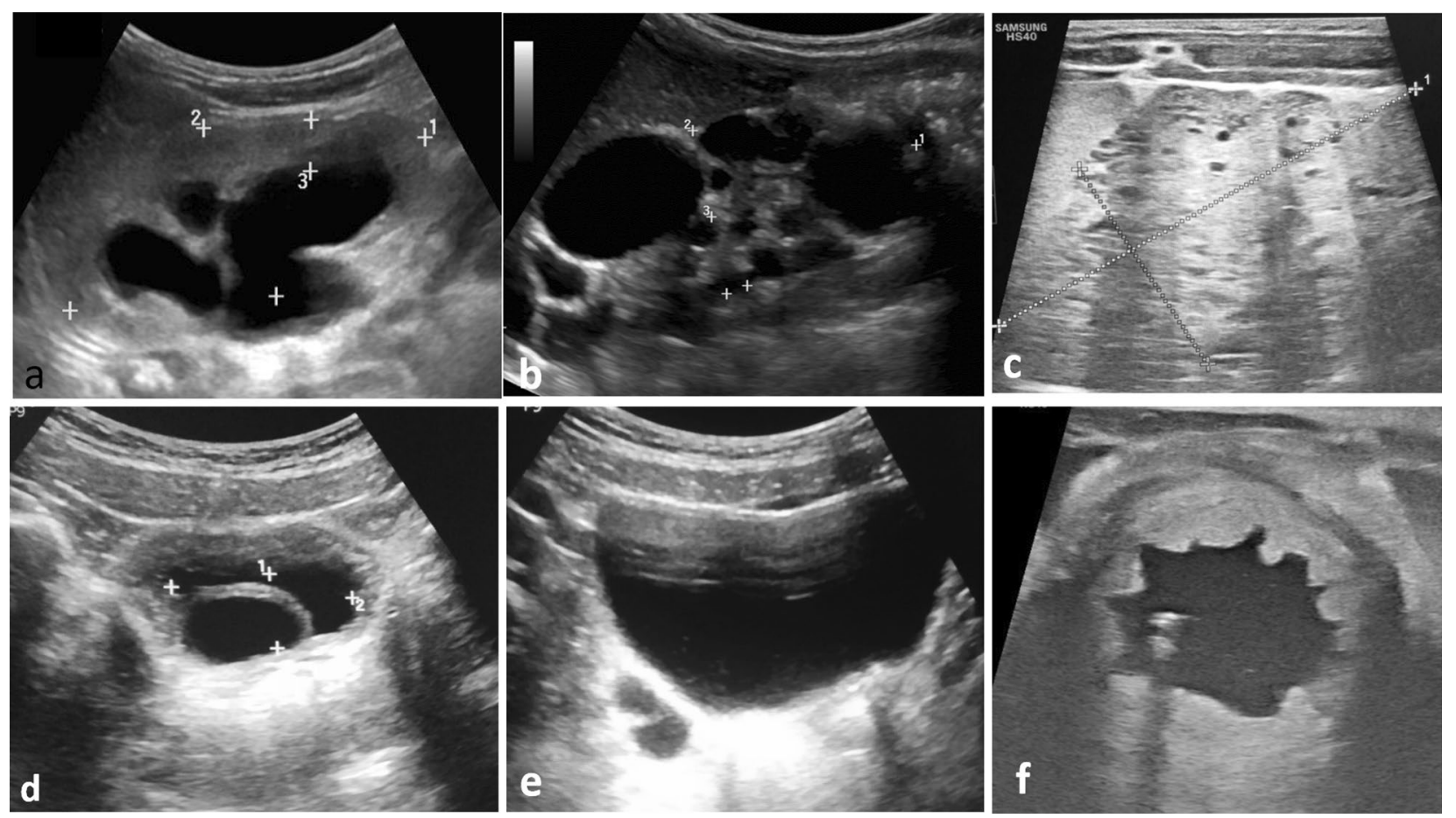

Fig. 1 Value of ultrasound in the initial assessment of the pediatric urinary tract a dilatation of the renal pelvis, central and peripheral calyces with poor corticomedullary differentiation (P3 UTD). b Multiple variable sized cysts in a case of multicystic dysplastic kidney. $\mathbf{c}$ Enlarged echogenic kidney with small cysts representing autosomal recessive polycystic kidney disease. $\mathbf{d}$ Ureterocele. $\mathbf{e}$ Double ureters near the urinary bladder. $\mathbf{f}$ Urinary bladder wall thickening and trabeculation in a case of posterior urethral valve

Table 2 Urinary tract dilatation grading system

\begin{tabular}{lllllllll}
\hline Grading & APRPD & Central calyces & Peripheral calyces & $\begin{array}{l}\text { Parenchymal } \\
\text { thickness }\end{array}$ & $\begin{array}{l}\text { Parenchymal } \\
\text { appearance }\end{array}$ & Ureters & Bladder & Risk \\
\hline Normal & Less than $10 \mathrm{~mm}$ & Normal & Normal & Normal & Normal & Normal & Normal & N/A \\
UTDP1 & $10-<15 \mathrm{~mm}$ & Dilated & Normal & Normal & Normal & Normal & Normal & Low \\
UTDP2 & $\geq 15 \mathrm{~mm}$ & Dilated & Dilated & Normal & Normal & Dilated & Normal & Intermediate \\
UTDP3 & $\geq 15 \mathrm{~mm}$ & Dilated & Dilated & Abnormal & Abnormal & Dilated & Abnormal & High \\
\hline
\end{tabular}

APRPD anteroposterior renal pelvis diameter, UTD urinary tract dilatation

three-dimensional (3D) ultrasound technologies provide higher spatial and temporal resolution with the potential to demonstrate complex anomalies. Moreover, 3D ultrasound can provide parenchymal volume calculations which were found to be comparable to those from scintigraphy and MR urography $[11,12]$.

After sonographic detection of UTD, micturating cystourethrography (MCUG) may be required for detection of vesicoureteric reflux (VUR) (especially in UTD 2 and 3). MCUG is the ideal imaging modality for detection and grading of VUR. In addition, posterior urethral valve can be readily diagnosed (Fig. 2) [2, 13]. However, radiation exposure, discomfort, relatively high cost and the risk of inducing urinary tract infection are main disadvantages of this technique [13]. However, contrast enhanced ultrasound voiding cystourethrography was found to be more sensitive in detecting VUR with good ability in evaluation of the urethra without the use of ionizing radiation [14].

If reflux is found, statistic cortical renal scintigraphy (Tc-99m-DMSA scintigraphy) is the investigation of choice for functional evaluation and determination of split renal function and detection of possible renal 


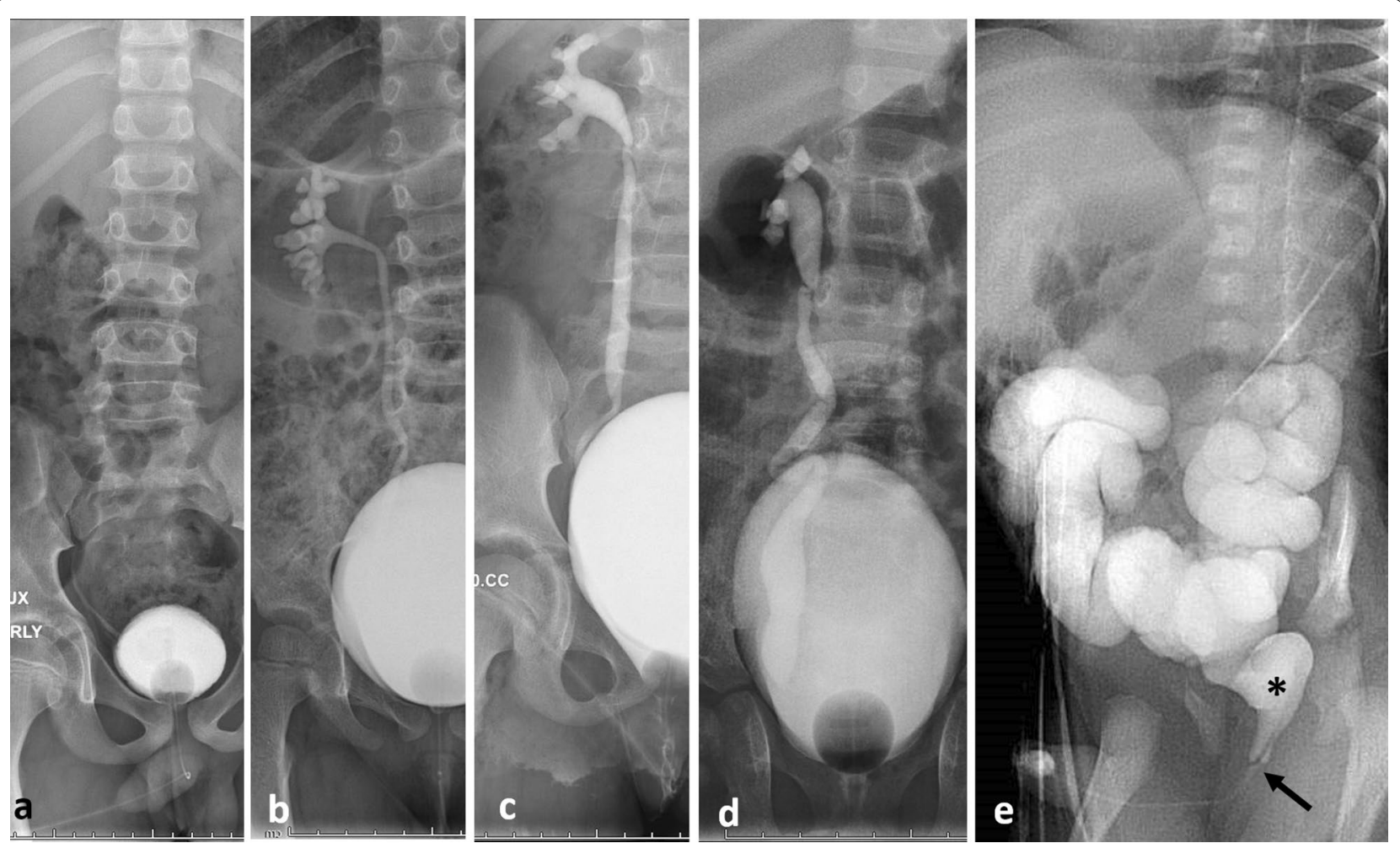

Fig. 2 different grades of vesicoureteral reflux elicited by micturating cystourethrography. Note bilateral grade 5 reflux and dilated posterior urethra (asterisk) in a case of posterior urethral valve (arrow)

scarring. If VUR is not encountered, so obstruction rather than reflux is the probable cause of UTD and dynamic renal scintigraphy (MAG-3 or DTPA scintigraphy) is the examination of choice to assess urodynamics of tracer excretion and determination of split renal function as well (Fig. 3) [15]. Caution should be taken when interpreting the slope of the time intensity curve of tracer excretion, as prolonged $\mathrm{T}$-half fails to differentiate poor drainage due to obstruction from that due to dilated nonobstructed collecting system [15].

MRI also can be requested especially in complex renal anomalies providing robust anatomical resolution with three-dimensional capabilities (Fig. 4) with proper detection of associated spinal anomalies (Fig. 5). MRI not only proving anatomical evaluation of the urinary tract, but also functional evaluation can be achieved if dynamic post-contrast study is performed (Figs. 6, 7, 8) [16]. In addition, fetal MRI is the appropriate next step after detection of fetal urinary tract dilatation specially if fetal intervention is available (Fig. 9) [17].
By using dynamic MRI urography, calculation of renal transit time (RTT) can be achieved. RTT helps estimate the presence of obstruction. RTT is defined as the time it takes for the contrast agent to pass from the renal cortex to the ureter below the lower pole of the kidney. If the transit time is less than $245 \mathrm{~s}$, the system is considered non-obstructive, while RTT greater than $490 \mathrm{~s}$ means probably obstructed system. If RTT times are between 245 and $490 \mathrm{~s}$, the obstruction is considered equivocal and is managed conservatively with close follow-up to ensure that renal function is stable (Figs. 6, 7, 8; Additional file 2: video 2) [16].

Hydronephrotic systems are classified as either compensated or decompensated based on the contrast dynamics and parenchymal changes. Signs of decompensated system include: signs of an acute-on-chronic obstruction with edema in the renal parenchyma seen as T2 hyperintensity; delay in excretion of contrast on the affected side with a delayed calyceal transit time; dense and persistent nephrogram; functionally, there is 


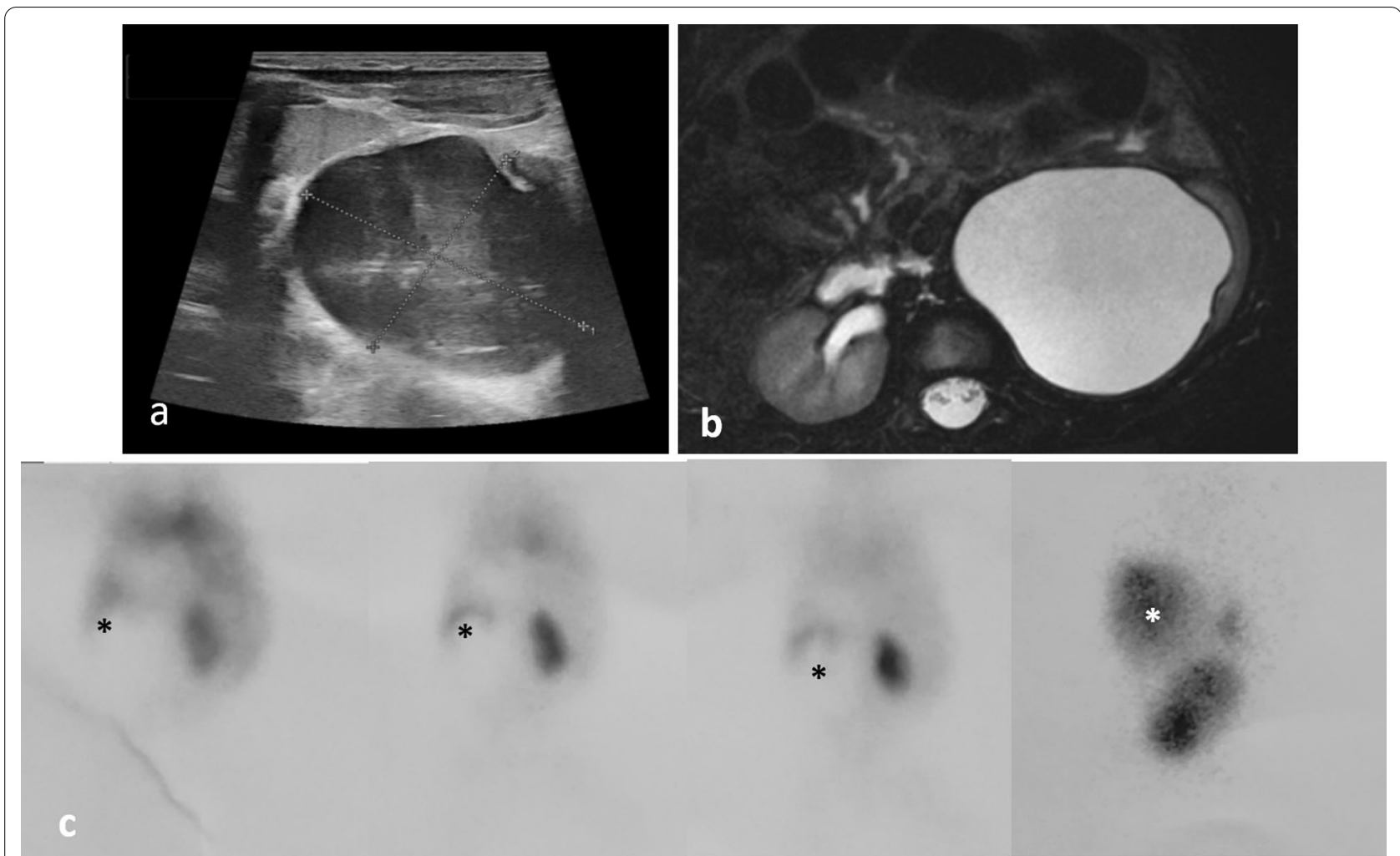

Fig. 3 A case of pelviureteric junction obstruction a ultrasound shows marked dilatation of the renal pelvis with marked thinning of the renal parenchyma. $\mathbf{b}$ axial high-resolution T2-WI of MRU protocol reveals dilated renal pelvis with parenchymal thinning, $\mathbf{c}$ Dynamic renal scintigraphy shows early photopenic area at the site of renal pelvis which fills of the tracer with time (asterisk)

a $4 \%$ discrepancy between the Patlak deferential renal function (pDRF) and the volumetric DRF (vDRF); and signal intensity versus time curves shows a persistent increase in signal intensity within the decompensated system (Fig. 7). However, signs of compensated hydronephrotic system that can accommodate the fluid challenge (Fig. 8) include symmetric calyceal transit time (time it takes for the contrast agent to pass from the renal cortex to the calyces); symmetric nephrograms and signal intensity versus time curves; and the pDRF and vDRF are within $4 \%$ points. In addition, MRI can detect signs of uropathy which include small subcortical cysts (Figs. 5, 9); poor cortico-medullary differentiation; decreased cortical signal intensity; and poorly defined or patchy nephrogram indicating impaired concentration $[18,19]$.
In resource constraint environment with limited access to MRI, intravenous pylography (IVP) might be requested to assess excretory renal function and areas of blockage of the urinary tract (Fig. 8). IVP can be requested in evaluation of post-operative urinary tract especially in cases of pelvi-ureteric junction obstruction [3].

\section{(B) Recurrent urinary tract infection}

Urinary tract infection (UTI) is the most common bacterial infection in children below two years of age. UTI is mostly attributed to congenital anomaly of the kidneys and urinary tract and probably vesicoureteral reflux. The diagnostic algorithm varies among different guidelines [20]. Ultrasound is indicated in all patients less than two years of age; or present with atypical or recurrent 

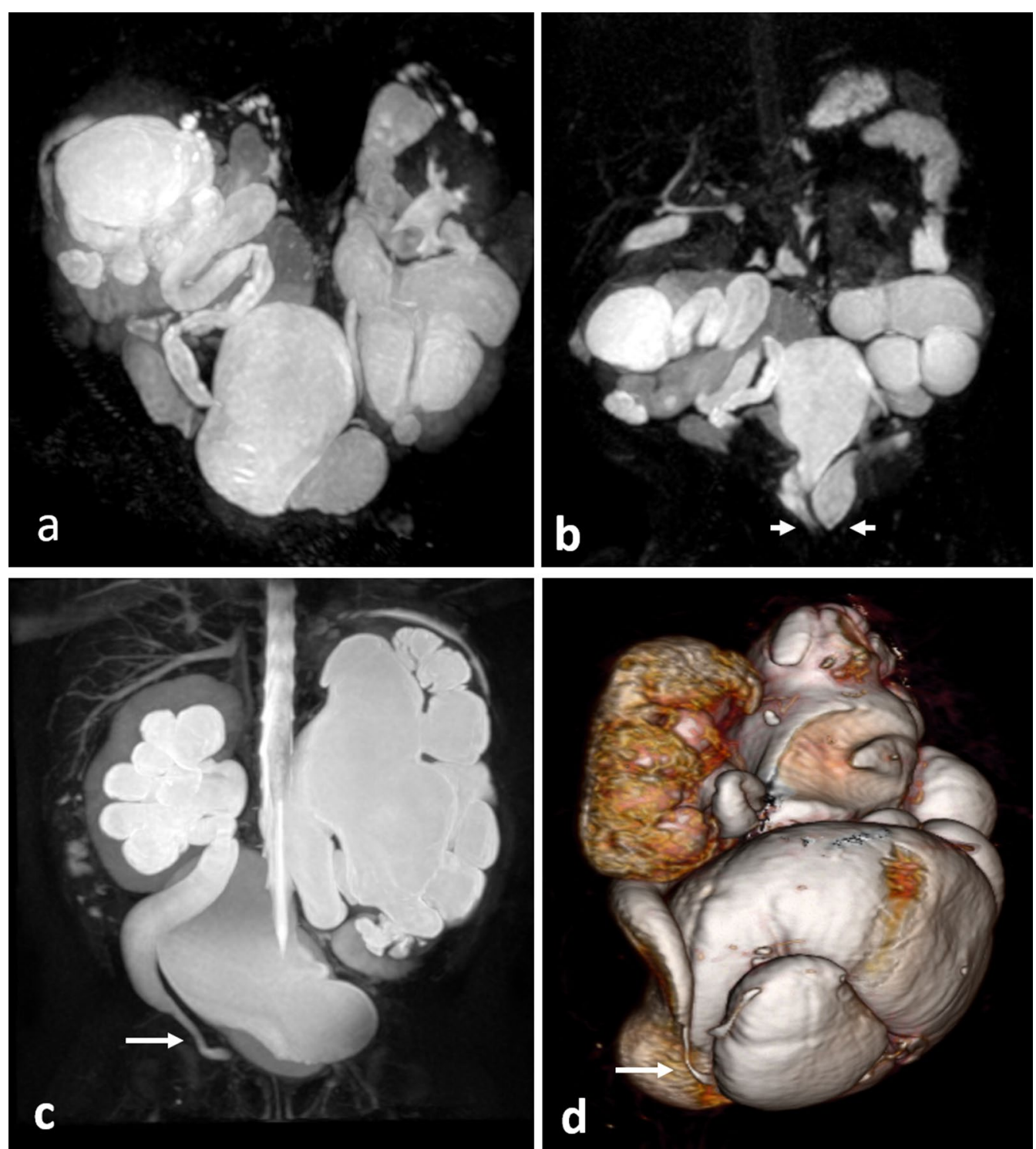

Fig. $4 \mathrm{MRU}$ in two cases with complex renal anomalies. a, b 1-month-old neonate with complex renal anomalies. Bilateral duplex system with ectopic ureteric insertions (arrow heads). The renal parenchyma of the upper moieties on both sides is thinned with multiple renal cysts. c, $\mathbf{d}$ MIP and 3D reformat show bilateral obstructive megaureter (note the distal ureteric narrowing characteristic of primary megaureter (arrow)

urinary tract infection. Most of the guidelines recommends that MCUG should be performed in all children with abnormal ultrasound or in cases with recurrent or atypical UTI. However, European Association of Urology and European Society for Pediatric Urology recommends further imaging only in all infants below one year with febrile UTI. They recommend MCUG, and if positive, DMSA scintigraphy (bottom-up approach); or DMSA scintigraphy and if positive MCUG (top-down approach).
In patients with recurrent UTI, DMSA scintigraphy should be performed 4 to 6 months after UTI [20].

\section{(C) Enuresis and daytime urinary incontinence}

Nocturnal enuresis (i.e., Enuresis) is defined as intermittent incontinence that occurs exclusively while asleep. According to the International Children's Continence Society, initial assessment of children with enuresis starts 


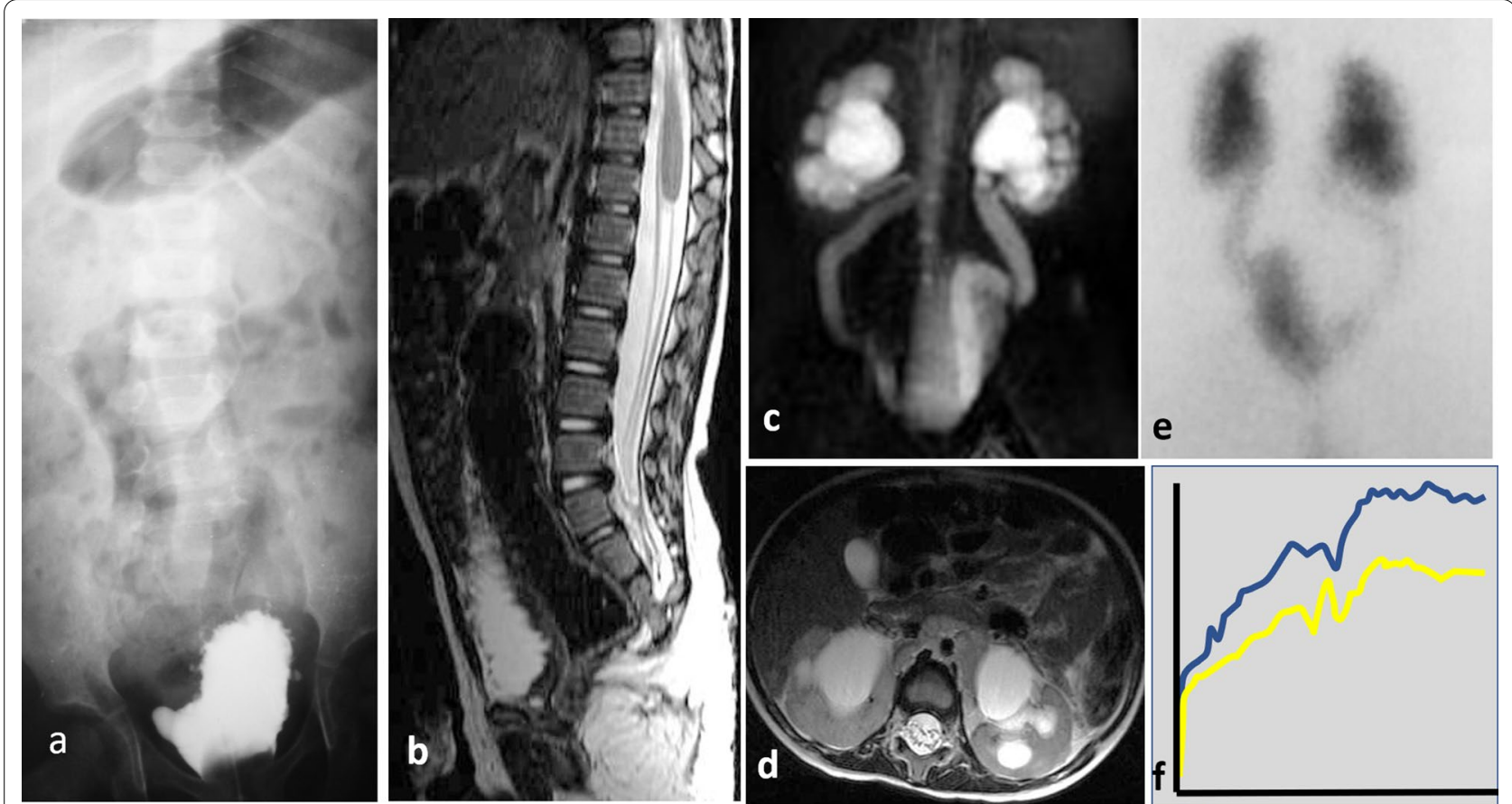

Fig. 5 4-year-old girl with history of anorectal anomaly, ultrasound revealed bilateral grade P3 hydronephrosis. a MCUG study reveals dysplastic sacrum, urinary bladder with multiple diverticulae with no evidence of reflux. $\mathbf{b}$ MRI sagittal spine shows evidence of caudal regression. $\mathbf{c}$ MRU shows bilateral hydroureter and hydronephrosis. $\mathbf{d}$ axial high-resolution T2WI shows dilatation of the renal pelvis, central and peripheral calyces. Renal parenchyma exhibits hyperintense signal with poor corticomedullary differentiation. e DTPA dynamic renal scintigraphy reveals retention of activity in both kidneys collecting systems and both ureters with plateau curve pattern (f)

with thorough clinical examination searching for warning signs. Management of enuresis depends upon whether it is monosymptomatic or nonmonosymptomatic. Associated symptoms in nonmonosymptomatic type can be daytime incontinence, urgency, voiding difficulties, abnormally low or high diurnal voiding frequency (less than four or more than seven times per day) [21].

Screening ultrasound should be done for all children with lower urinary tract dysfunction. The bladder should be scanned when full (pre-void scan) and immediately after emptying (post-void scan). This contributes to assessment of the bladder capacity, wall thickness, bladder neck appearance, evaluation of distal ureters; and post-void residual urine, respectively. In addition, transverse rectal diameter can be measured behind the bladder. Transverse rectal diameter more than $30 \mathrm{~mm}$ could indicate fecal impaction and constipation. Children with dysfunctional voiding have high prevalence of constipation serving as an etiological factor for incontinence [22].
MRI of the spine is reserved for children with suspected abnormalities of the lumbosacral spine (Fig. 5). MR urography can be of value in detection of structural anomalies particularly ectopic ureter [16]. IVP may be of value if the access to MRI is limited (Fig. 10).

\section{(D) Abdominal masses}

Palpable abdominal mass is the most common presenting sign of pediatric renal malignancy necessitating ultrasound examination. Following ultrasound, crosssectional imaging with CT or MRI is mandatory for further evaluation and initial staging. Because of its wider availability and its shorter scan time, CT is the most used imaging modality. CT also enables simultaneous evaluation of both lungs. MRI lacks ionizing radiation with better soft tissue resolution. Children's oncology group found similar diagnostic performance of CT and MRI in terms of detection of lymph node metastasis and 


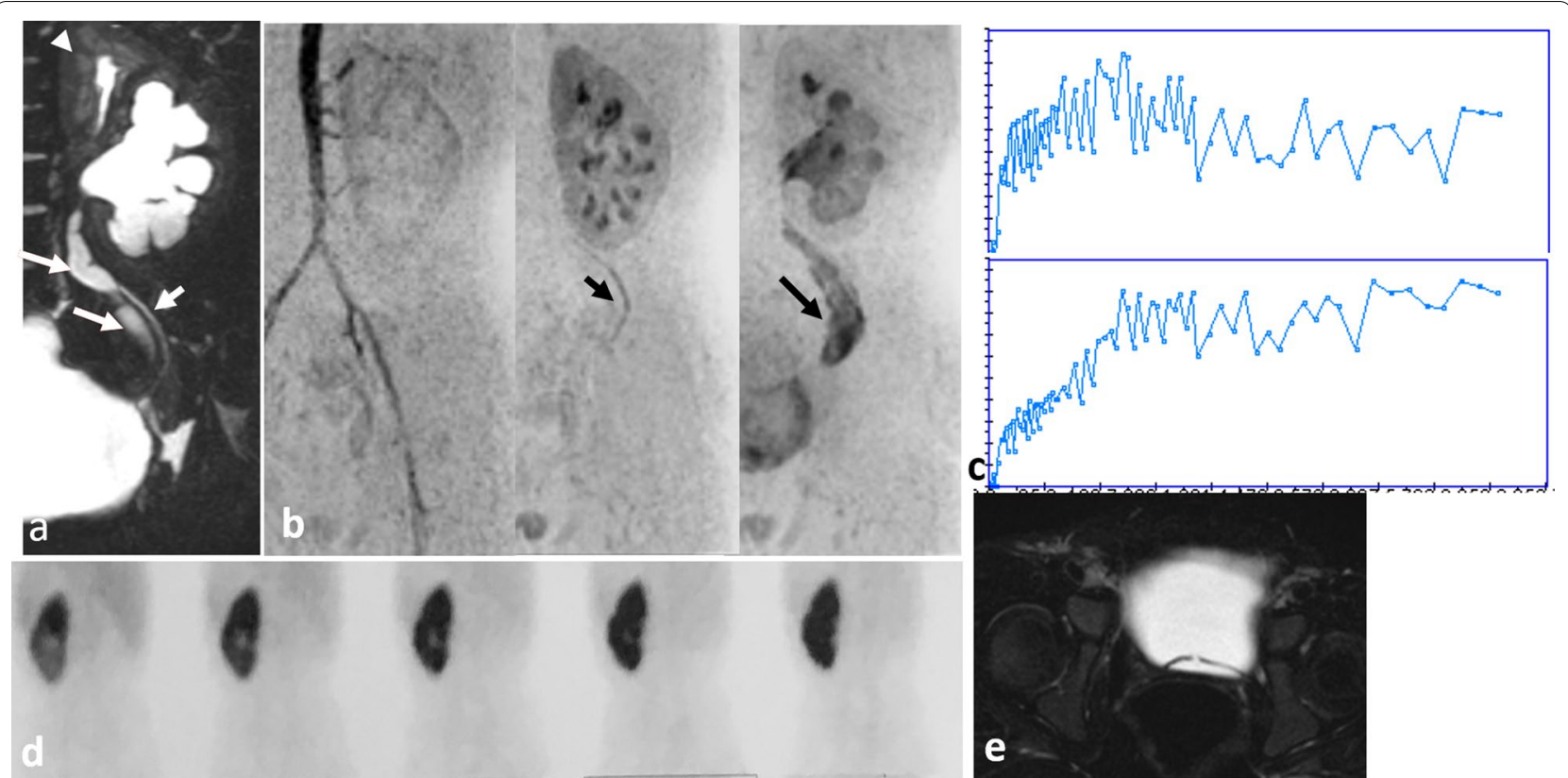

Fig. 6 2-year-old boy with history of recurrent UTI with history of right nephrectomy and left renal duplex system and ureterocele underwent incision. a Coronal MRU reveals preserved parenchyma of the upper moiety (arrowhead) and P3 UTD the lower moiety (associated with ureteric dilatation (long arrows). Note relative parenchymal thinning of the lower moiety compared to the upper one. The ureter of the upper moiety is not dilated (short arrow). b Dynamic MRU reveals a multiple blood vessels rather than single renal artery supplying the left kidney; normal excretory function of the upper moiety with earlier appearance of the right ureter (short arrow); relatively mild delay in contrast excretion into the ureter of the lower moiety (long arrow). RTT of the upper pole $=171$, lower pole $=251 \mathrm{~s}$. c Time intensity curve of the upper moiety shows normal drainage (upper curve), while there is plateau curve of the lower moiety (lower curve). $\mathbf{d}$ DTPA dynamic renal scintigraphy shows early photopenic area at the region of the lower moiety which fills up with tracer. e Axial MRU shows the incised ureterocele

capsular invasion. However, MRI was found to be more sensitive in detecting contralateral synchronous masses (Fig. 11) [23]. Being patient specific, 3-D printed models have been found to be valuable surgical planning tool especially for complex kidney tumors [24].

\section{(E)Flank pain}

Acute abdominal pain is a common complaint of patients presenting to the emergency department. It is defined as pain with a maximum duration of 5 days with no evidence of trauma. When acute abdominal pain is associated with normal appetite, renal tenderness and/ or hematuria (more than 10 erythrocytes), acute renal colic should be considered [25]. While typical renal colic presents in school-aged children and adolescence, inconsolable crying and irritability are typical signs in infancy.

Ultrasound and radiography are the imaging modalities of choice. Ultrasound can demonstrate the presence, position, and dimensions of renal calculi. Most stones are usually found in the pelvicalyceal system, proximal or distal ureter. Ultrasound evidence of lithiasis includes shadowing echogenic foci, urinary tract dilatation, and increased renal parenchymal echogenicity (Figs. 12, 13). Colour Doppler ultrasound can elicit twinkle artifact with increased resistive index on Duplex Doppler in cases with acute severe obstruction. Due to radiation burden, low-dose non-contrast CT should be reserved when ultrasound is non-diagnostic or further anatomical details are needed for surgical intervention (Figs. 12, 13, 14) [26]. 

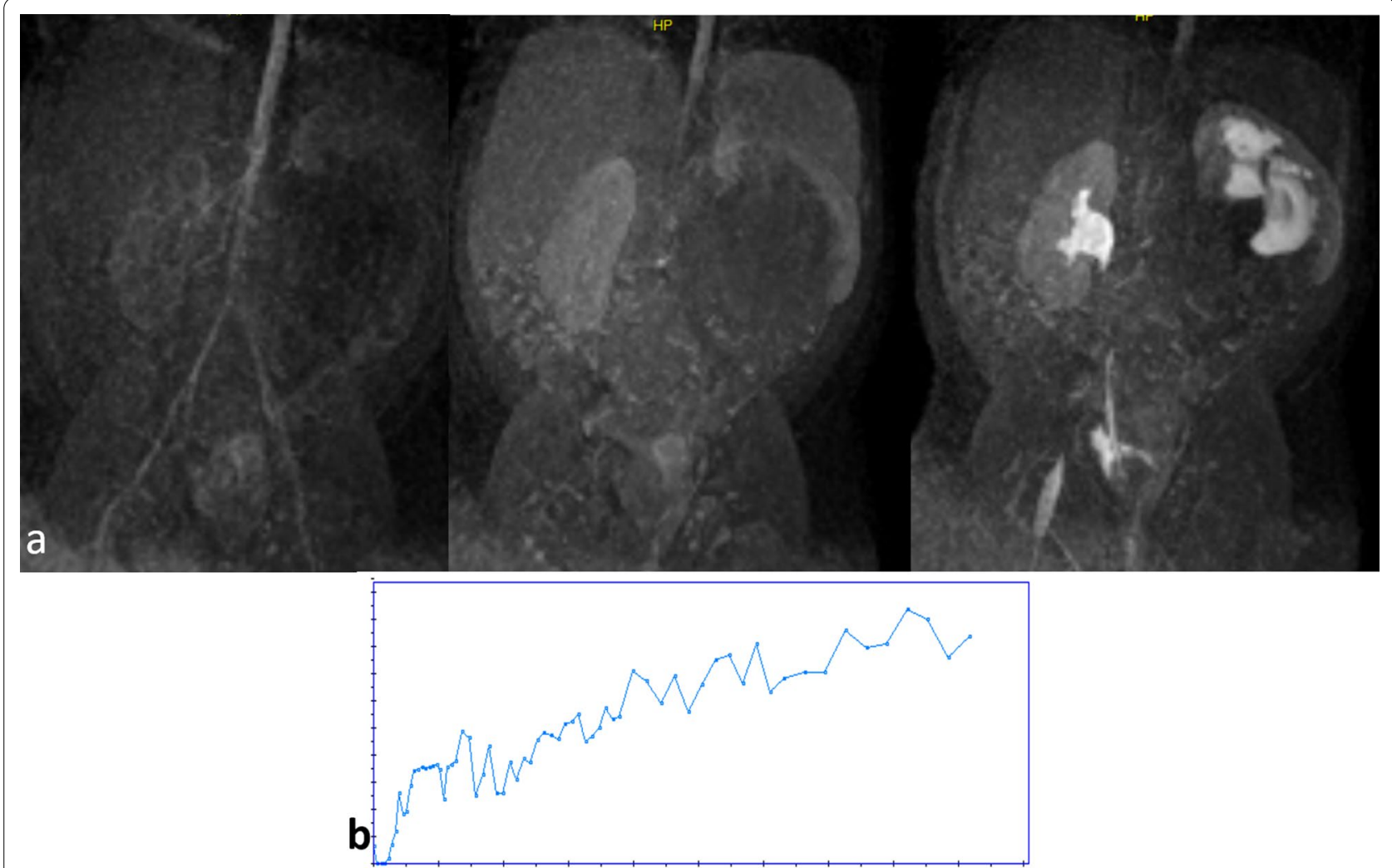

Fig. 7 Dynamic postcontrast MRU of the same case at Fig. 3 left PUJ with left PUJ obstruction. The study reveals delayed cortical enhancement on the left with delayed visualization of the left ureter. Time intensity curves reveal the obstructive pattern on the left side $(L)$ with prolonged RTT more than $15 \mathrm{~min}$
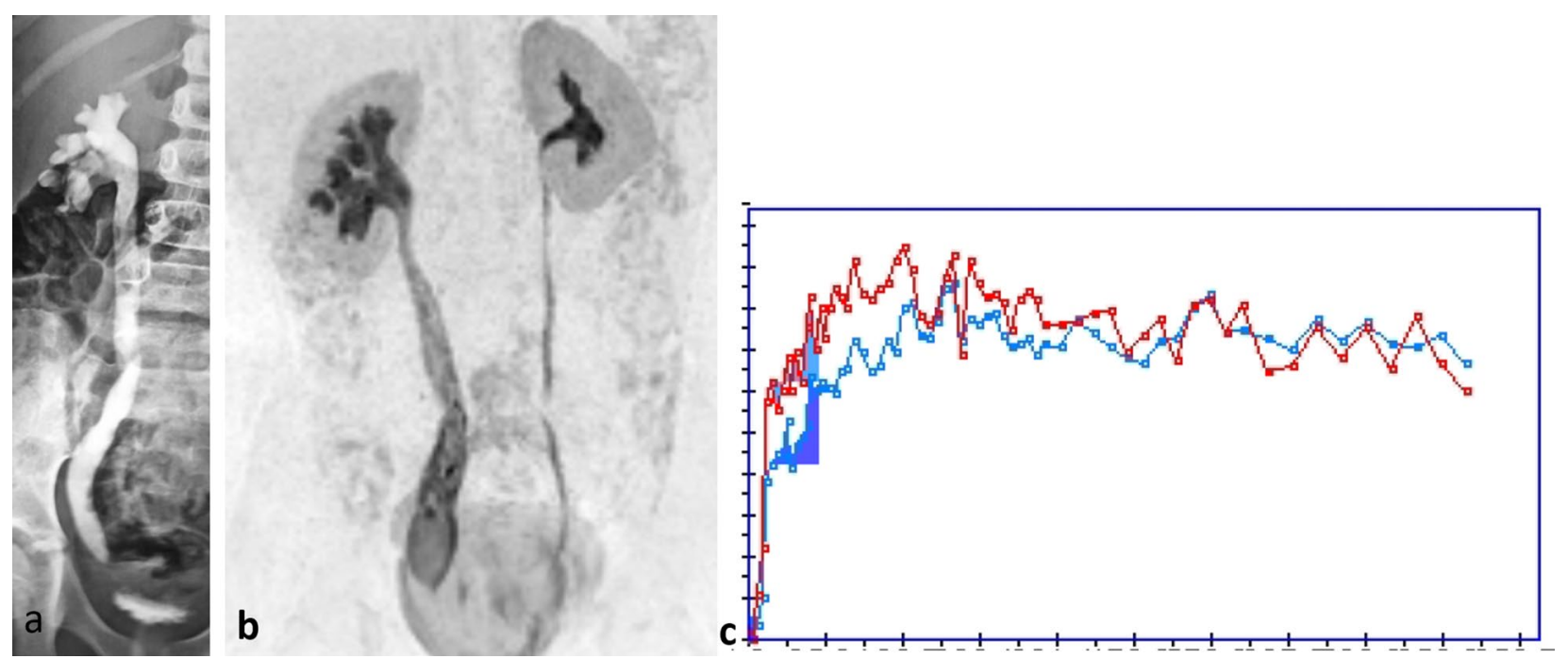

Fig. 8 4-year-old girl with right sided urinary tract dilatation (P3) (hydroureter and hydronephrosis) due to primary megaureter. MCUG was unremarkable. She underwent IVP elsewhere (a) and confirms presence of hydroureter and hydronephrosis in addition to hold up of the contrast at the distal ureteric end. $\mathbf{b}$ Dynamic MRU at our institution confirms the same findings with symmetric nephrograms and signal intensity versus time curves (c) with symmetric calyceal transit time (99 s) indicating compensated hydronephrotic system 


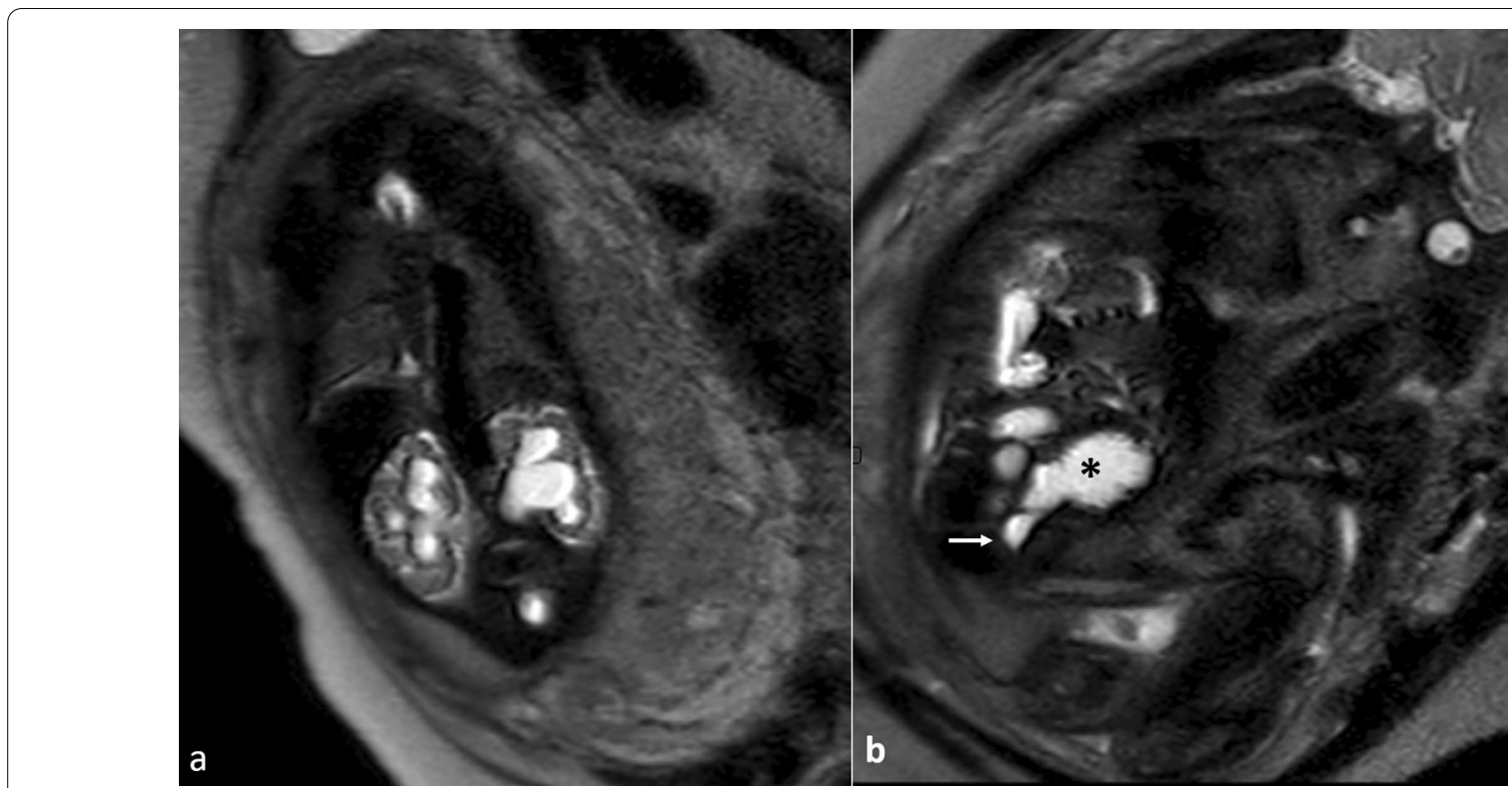

Fig. 9 28-week fetus with urinary tract dilatation (A2-3) associating posterior urethral valve. a Coronal BFFE reveals thinning of the renal parenchyma, poor corticomedullary differentiation, tiny renal cortical cysts. b sagittal BFFE reveals thick trabeculated urinary bladder wall (asterisk) with dilated posterior urethra (arrow). Oligohydramnios is also seen

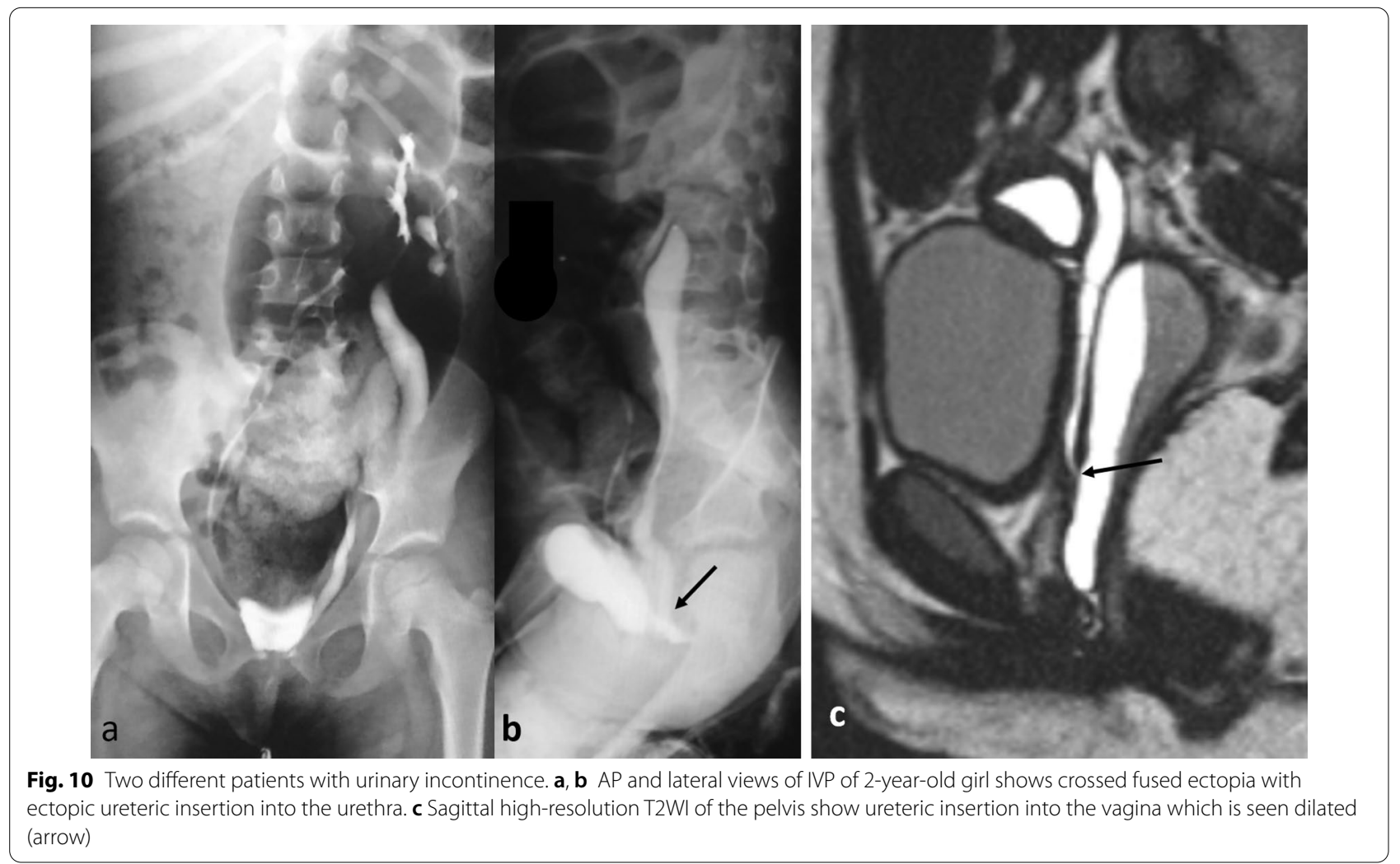



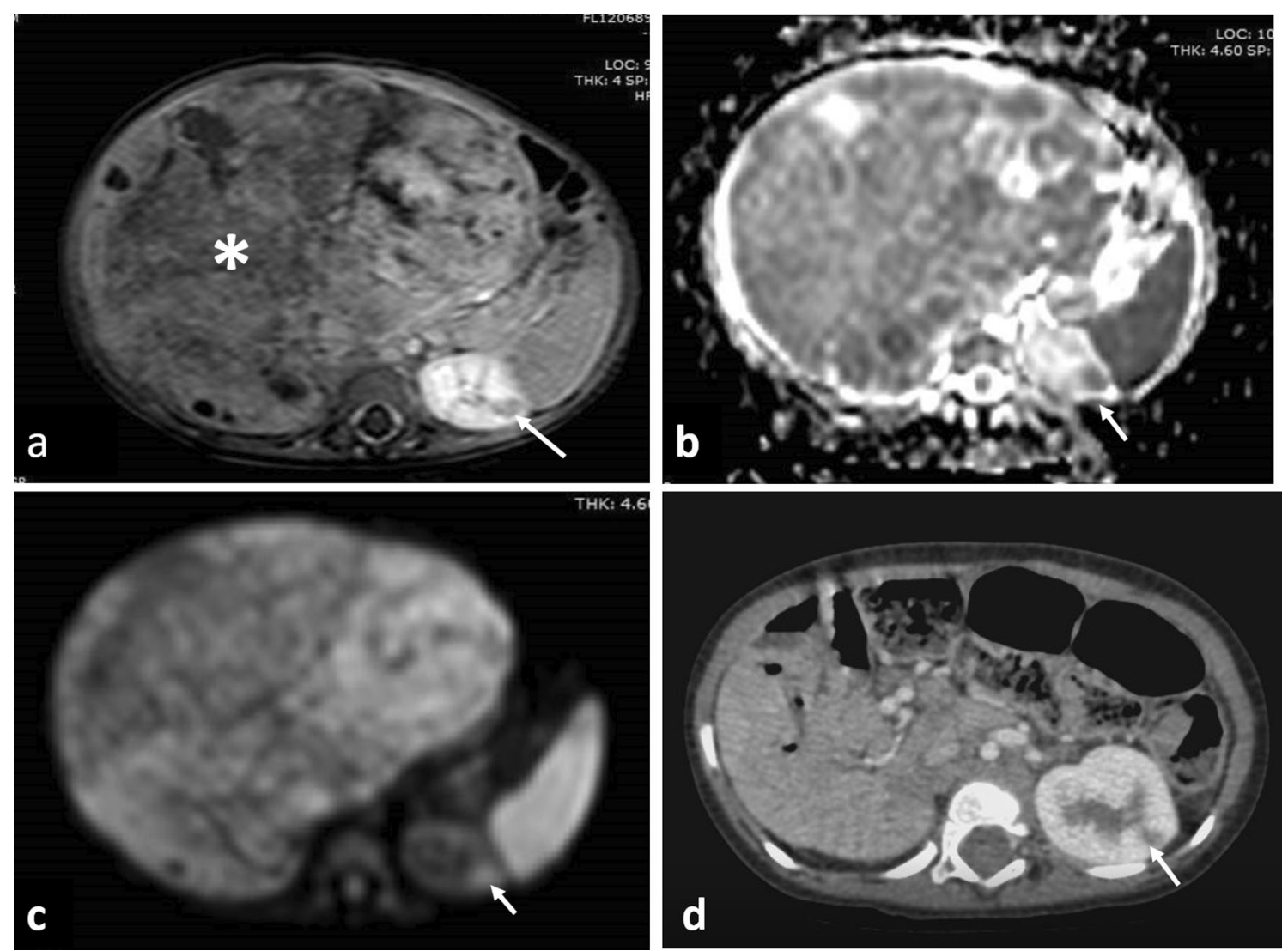

Fig. 11 11-month-old boy with right Wim's tumor and foci of nephrogenic rests on the left side. a Preoperative post-contrast Fat Sat. T1WI shows a large heterogeneously enhancing renal tumor on the right side (asterisk). The nephrogenic rest on the left side is hypo-enhancing compared to renal tissue (arrow) b, c ADC and DWI, respectively, showing the Wilms tumor (asterisk) and nephrogenic rests (arrow) exhibiting diffusion restriction. $\mathbf{d}$ Follow up CT ten months after surgery showing stationary appearance of the nephrogenic rest (arrow)

\section{(F)Hematuria}

Hematuria is relatively a common and alarming complaints in children. It comes into attention as incidental finding of urine analysis (microscopic hematuria), or when gross hematuria is evident (macroscopic hematuria). The management of hematuria starts with identifying the underlying etiology [27]. A stepwise approach for managing cases with hematuria has been developed [2]. After through clinical examination and performing necessary laboratory investigations (urine analysis and culture, serum creatinine and blood urea nitrogen), ultrasound is the first recommended imaging modality searching for structural urinary abnormalities (renal echogenity, urolithiasis, renal vein thrombosis or masses)
$[2,27]$. Subsequent imaging depends on the initial ultrasound findings. While urinary bladder inflammatory process or glomerulonephritis are the most common causes of gross hematuria, it can be caused by lithiasis or by the rare urinary bladder rhabdomyosarcoma (Fig. 15).

\section{(G) Trauma}

Imaging plays a pivotal role in managing patients who have experienced blunt or penetrating genitourinary injury. Being fast and bedside imaging modality, Ultrasound is the first modality for trauma surveillance especially in patients with minimal symptoms. In cases of urinary tract injury four-phase post-contrast CT of the urinary tract is recommended. Pre- and post-contrast 

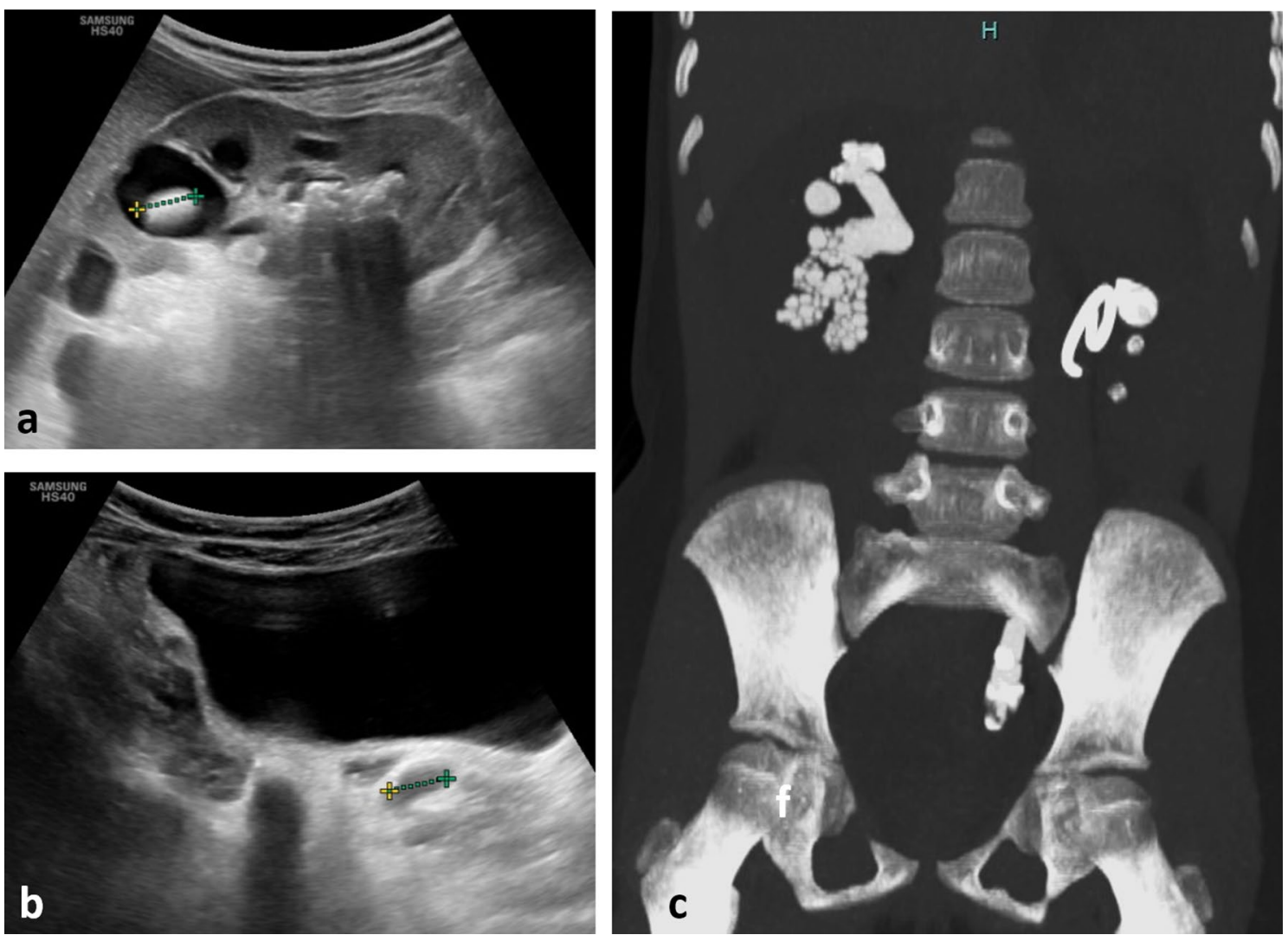

b

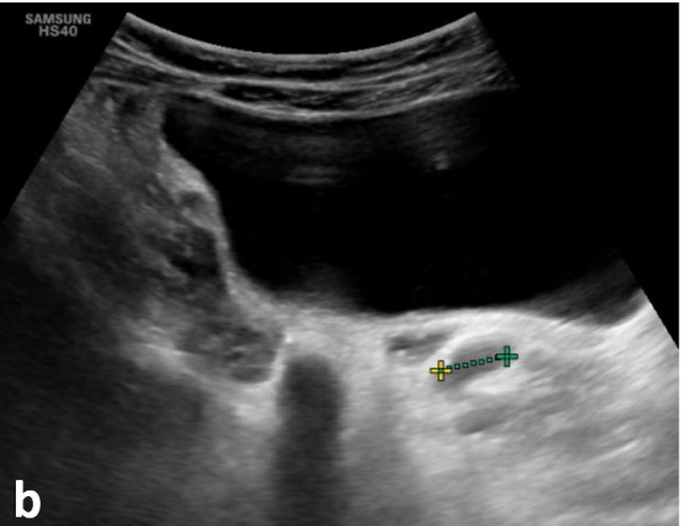

C

Fig. 12 8-year-old girl with multiple stones a renal ultrasound reveals multiple stones filling the calyces and renal pelvis appears as dense echogenic foci with acoustic shadowing. $\mathbf{b}$ longitudinal ultrasound through the pelvis shows multiple stones at the distal ureter as well. Owing to complexity of the case, $\mathbf{c}$ non-contrast $\mathrm{CT}$ of the urinary tract is requested prior to surgical intervention and reveals multiple bilateral renal and left ureteric stones

phases in arterial, nephrographic and pyelographic phases are acquired (Fig. 16) [4].

(H) Nonpalpable testis, ambiguous genitalia and common urogenital sinus anomalies (UGS)

Nonpalpable testis represents failure of normal testicular descent. The nonpalpable testis is located either in intraabdominal or extrabdominal location. Ultrasound is initially employed in imaging pathway being able to detect $97 \%$ of viable inguinal testes. However, ultrasound can't reliably detect intraabdominal testes which represent $20 \%$ of nonpalpable testes. Moreover, MRI can't diagnose monorchidism. Consequently, both the American Urologic Association and European Association of Urology Guidelines recommend against imaging for the routine management of patients with nonpalpable testis $[28,29]$. Nevertheless, cases with nonpalpable testes associating ambiguous genitalia or hypospadias have a great likelihood of having disorder of sexual development. For this instance, ultrasound or MRI is recommended to look for internal female pelvic organs especially the uterus [30]

Common UGS is a term used to describe an anomaly in the female when the urethra and vagina unite in a common urogenital channel that opens into the perineum via a single opening. Common UGS may be broadly classified into two main types: those associated with abnormal virilization, and the other non-virilized type (cloaca) [31, 32].

Virilized common urogenital sinus anomalies is one of disorders of sexual development associating congenital adrenal hyperplasia. The diagnosis depends on clinical presentation, chromosomal analysis, and specific hormonal profile. Non-virilized common urogenital sinus anomalies are essentially associated with anorectal anomalies (cloaca malformation) which further adds to the complexity and diversity of the spectrum. The genitogram represents the main preoperative radiological 

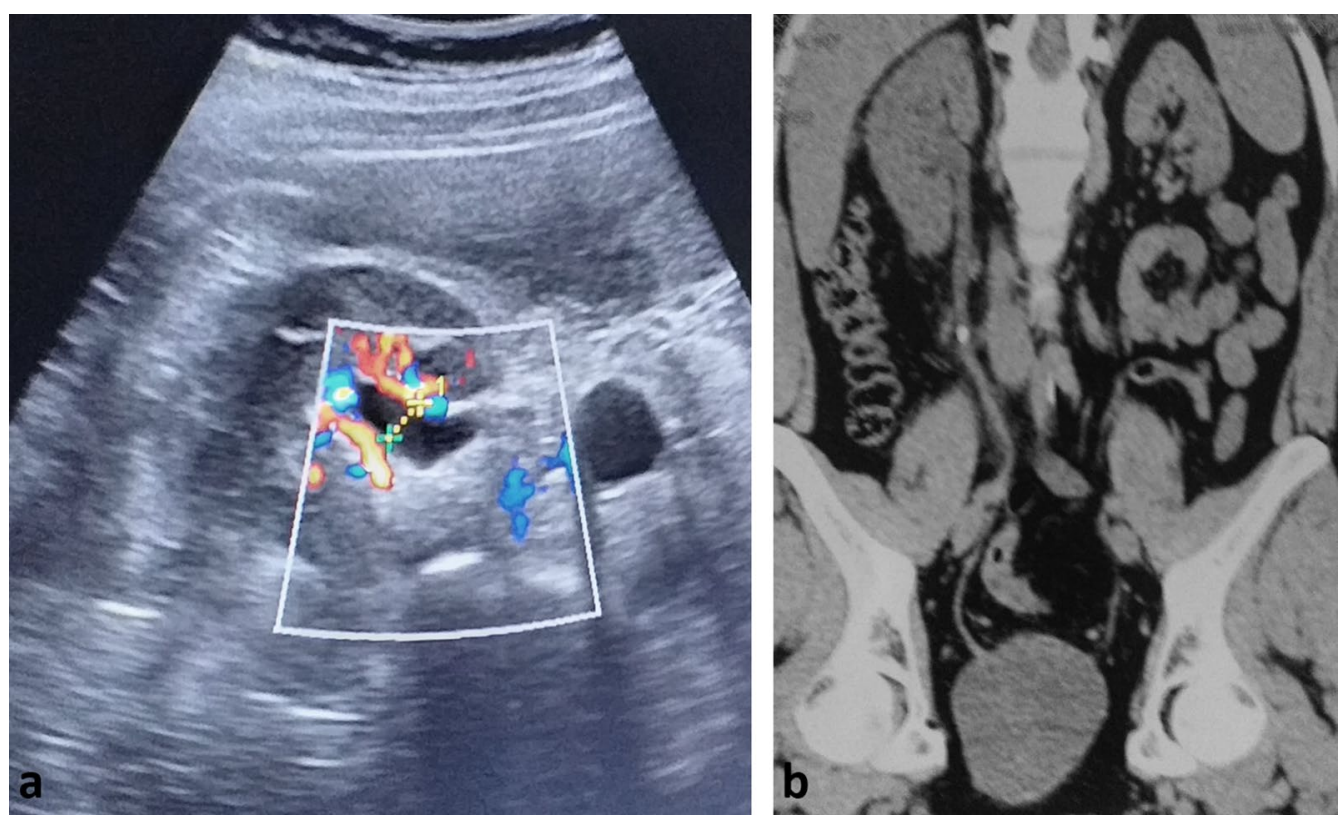

Fig. 13 Ultrasound in the setting of acute ureteric colic showing mild dilatation of the renal pelvis (a); $\mathbf{b}$ non-contrast CT shows stone at the mid ureter
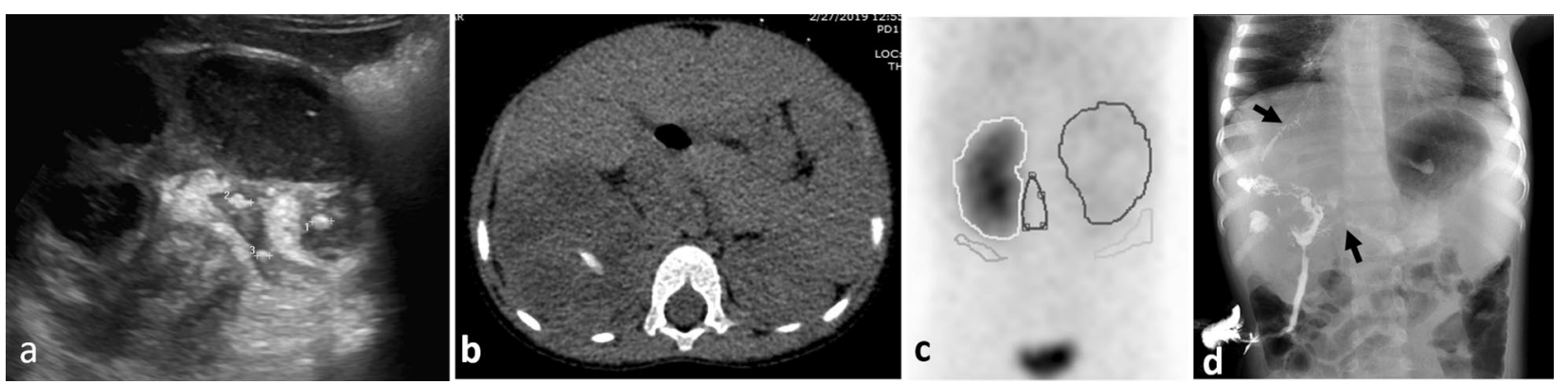

Fig. 14 3-year-old girl with history of recurrent urinary tract infection and right loin pain and diagnosed as Xanthogranulomatous pyelonephritis with fistulous communication to the airway and duodenum. a Ultrasound reveals distorted renal parenchyma with multiple echogenic stones with paradoxically contracted renal pelvis. b Axial non-contrast CT reveals enlarged right kidney with multiple necrotic areas and a central stone. The inflammatory process extends to the perinephric region and right psoas muscle. c DTPA scintigraphy reveals normal uptake in the normal left kidney and no uptake in the right kidney. $\mathbf{d}$ Fistulography through a cutaneous opening reveals multiple fistulous tracts communicating with the bronchial tree, and duodenum (arrows)

assessment for urogenital sinus anomalies. The level of urogenital confluence, length of the urethra, length of common channel, and the degree of development of the vagina can be determined. Recently, some centres may add pelvic MRI as a useful complementary tool to demonstrate the internal pelvic anatomy in multiple sequences and planes (Figs. 17, 18). This is important for preoperative counselling when deciding about the type and extent of reconstructive surgery. Moreover, ultrasound of the upper urinary tract is of paramount importance to detect and follow-up associated urinary tract dilatation in cases of cloaca [32, 33]. 


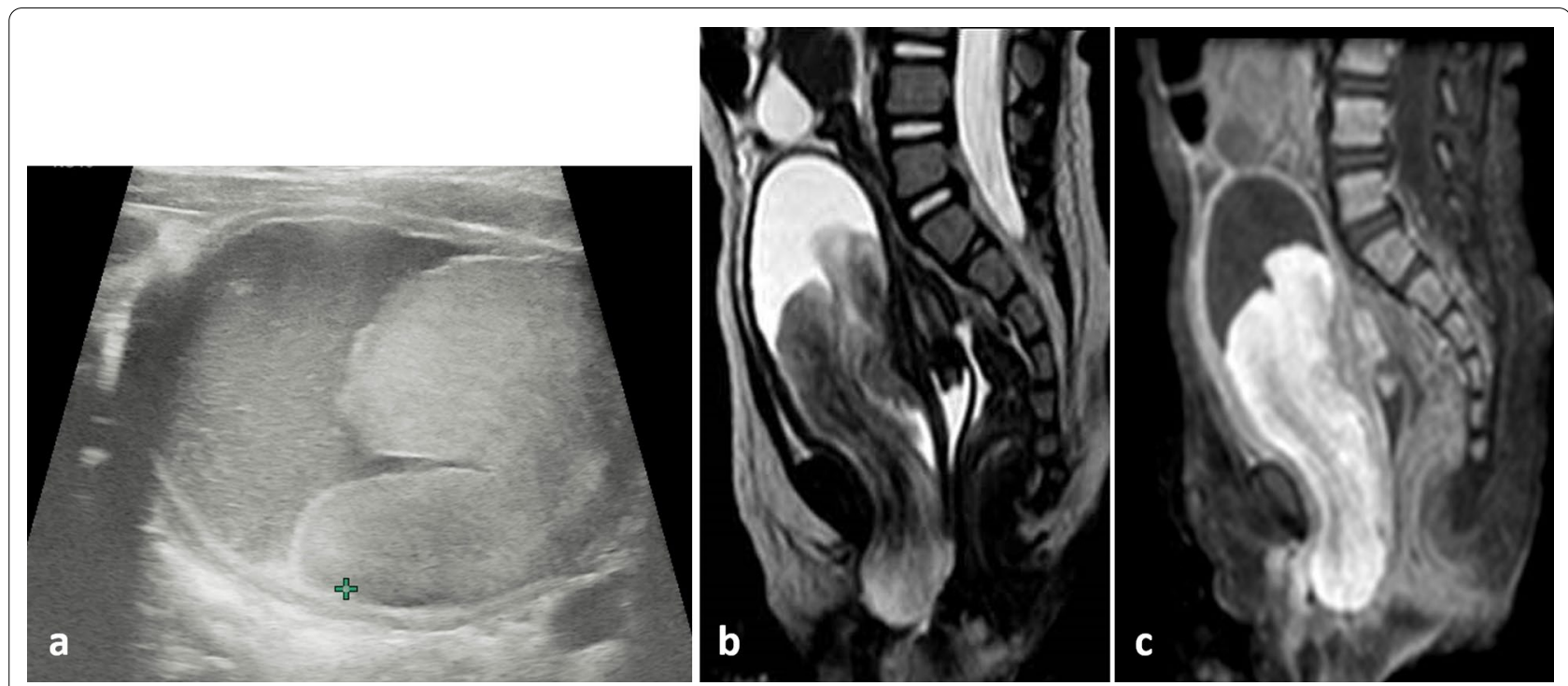

Fig. 15 15-month-old girl with hematuria and diagnosed with urinary bladder rhabdomyosarcoma. a Ultrasound shows a large mass protruding into the urinary ladder. $\mathbf{b}$ Sagittal T2-WI and $\mathbf{c}$ sagittal fat sat post-contrast T1-WI confirms the presence of the mass with better demonstration of its extension and mass effect (note the fluid filled vagina (asterisk)
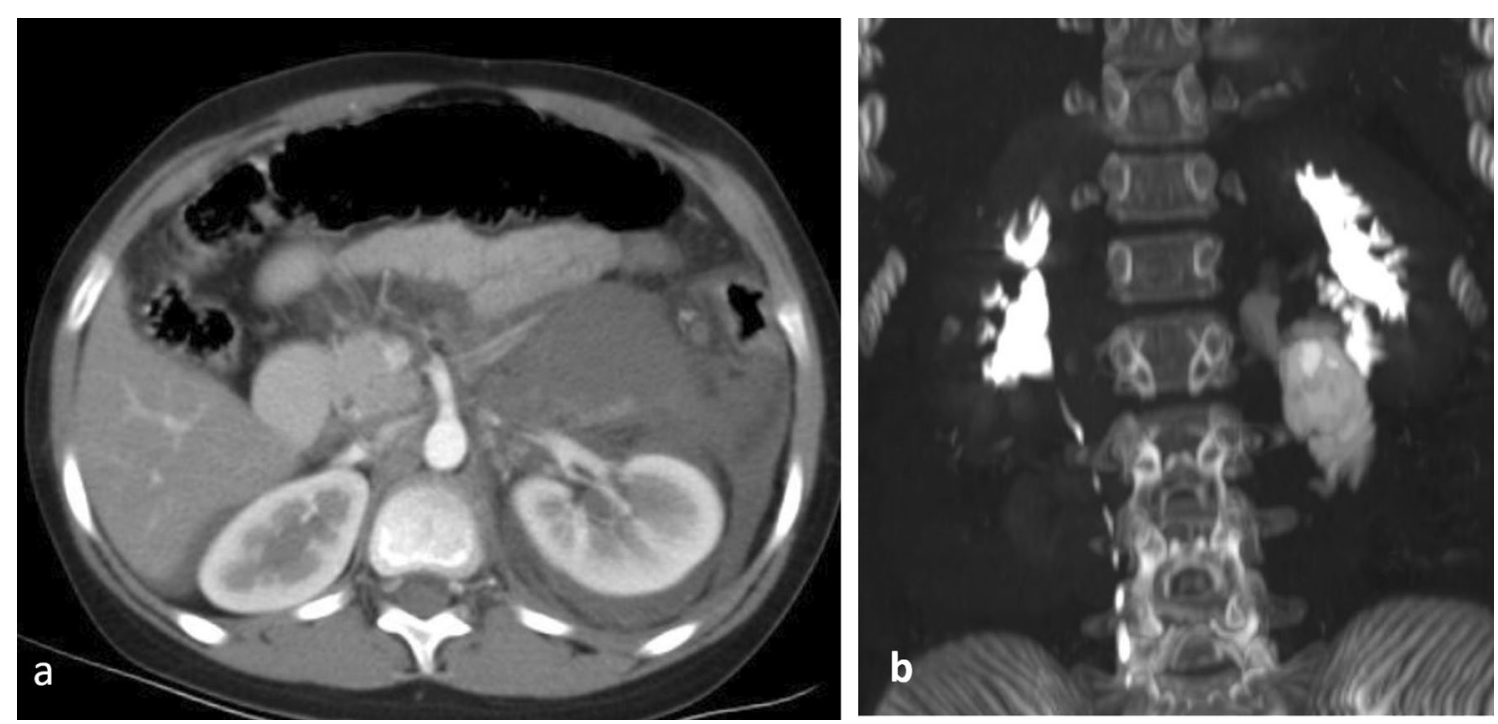

Fig. 16 12-year-old female with history of trauma. Ultrasound reveals perinephric collection (not shown). a Axial CT post-contrast at the nephrographic phase confirms the presence of perinephric collection. $\mathbf{b}$ Coronal MIP of the delayed excretory phase shows contrast extravasation from the injured pelvi-urerteric junction

\section{(I)Renovascular hypertension}

Renovascular hypertension is suspected when hypertension is severe or refractory to multiple drugs. Ultrasound is the initial imaging modality. Abnormally low resistive index less than 0.5 and tardus parvus pattern of spectral Doppler waveform with slow systolic acceleration and decreased peak systelic velocity have been used either isolated or in combination as an indicator for diagnosis of renal artery stenosis (Fig. 18). Ultrasound can also detect renal parenchymal abnormality and non-renal 

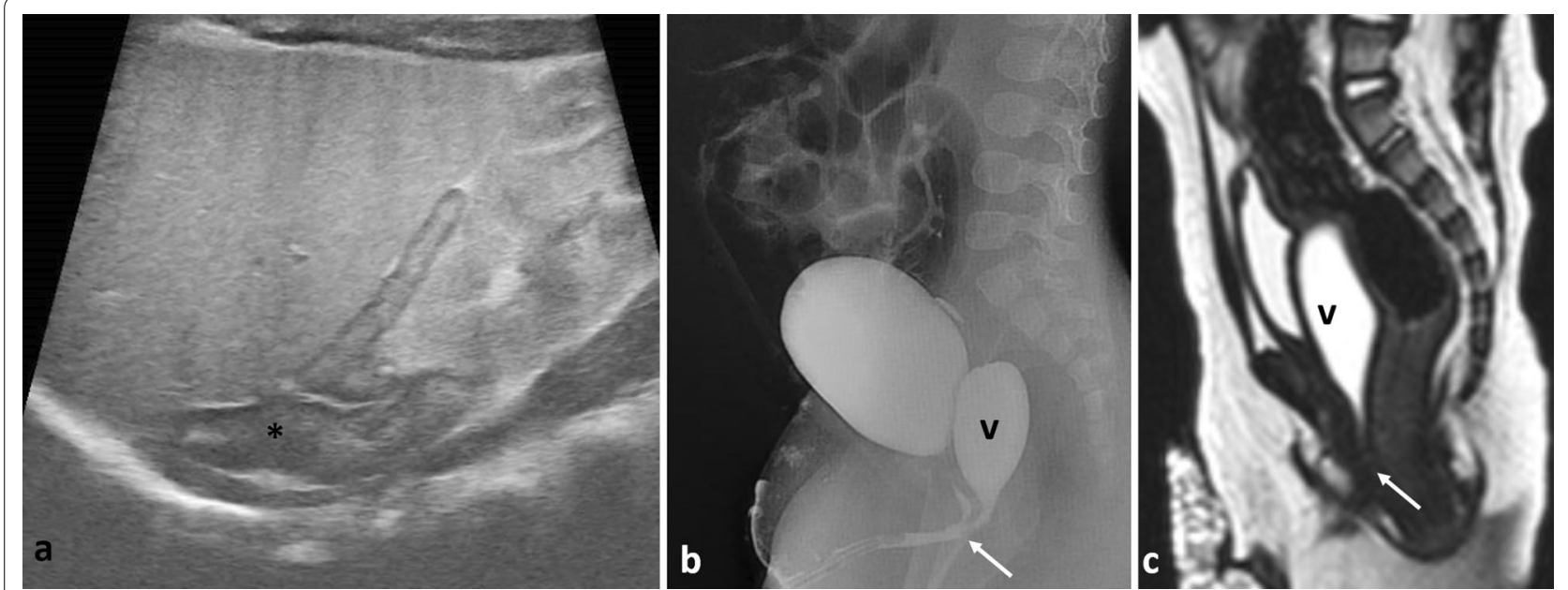

Fig. 17 Imaging of congenital adrenal hyperplasia a ultrasound showing enlarged suprarenal gland having cerebriform pattern (asterisk); b, c genitography and sagittal T2WI MRI showing confluence of the distended vagina and urinary bladder into the common urogenital sinus (arrow). $V$ vagina
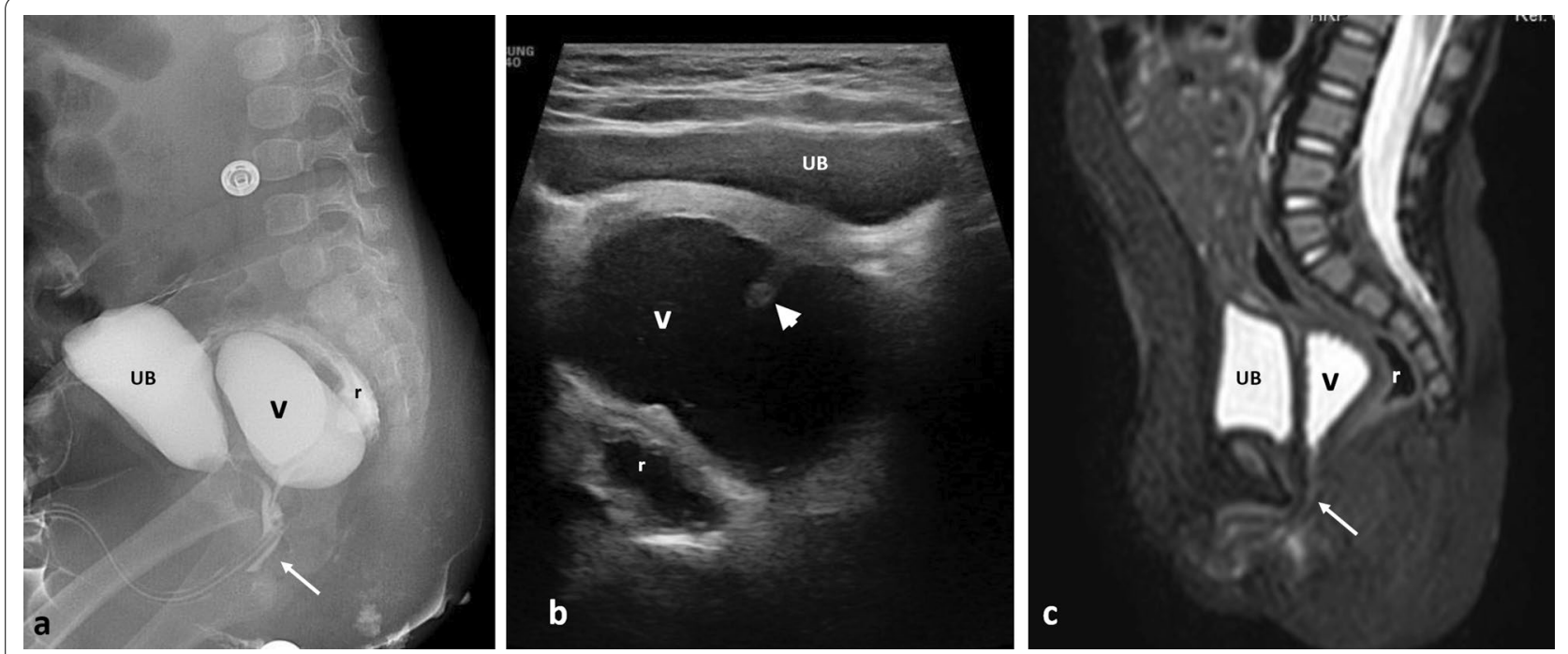

Fig. 18 Imaging of cloaca malformation. a, b genitography and ultrasound of 7-month-old girl with cloaca malformation showing distended vagina (asterisk) with incomplete vaginal septum (short arrow) with a long cloaca channel (long arrow). c Sagittal STIR MRI of 9-month-old girl with cloaca showing confluence of the rectum, distended vagina and bladder into a common cloaca channel (long arrow). $r$ rectum, $v$ vagina, UB urinary bladder

causes of hypertension as pheochromocytoma [34]. However, positive, or negative ultrasound can't preclude further imaging investigation especially in cases with moderate to severe suspicion of renovascular hypertension. CT or MR angiography is the recommended further imaging modalities (Fig. 19). Children are referred for catheter renal angiography after failure of medical therapy for hypertension or when ultrasound reveals size discrepancy between both kidneys, and in children with neurofibromatosis. Catheter angiography is more 

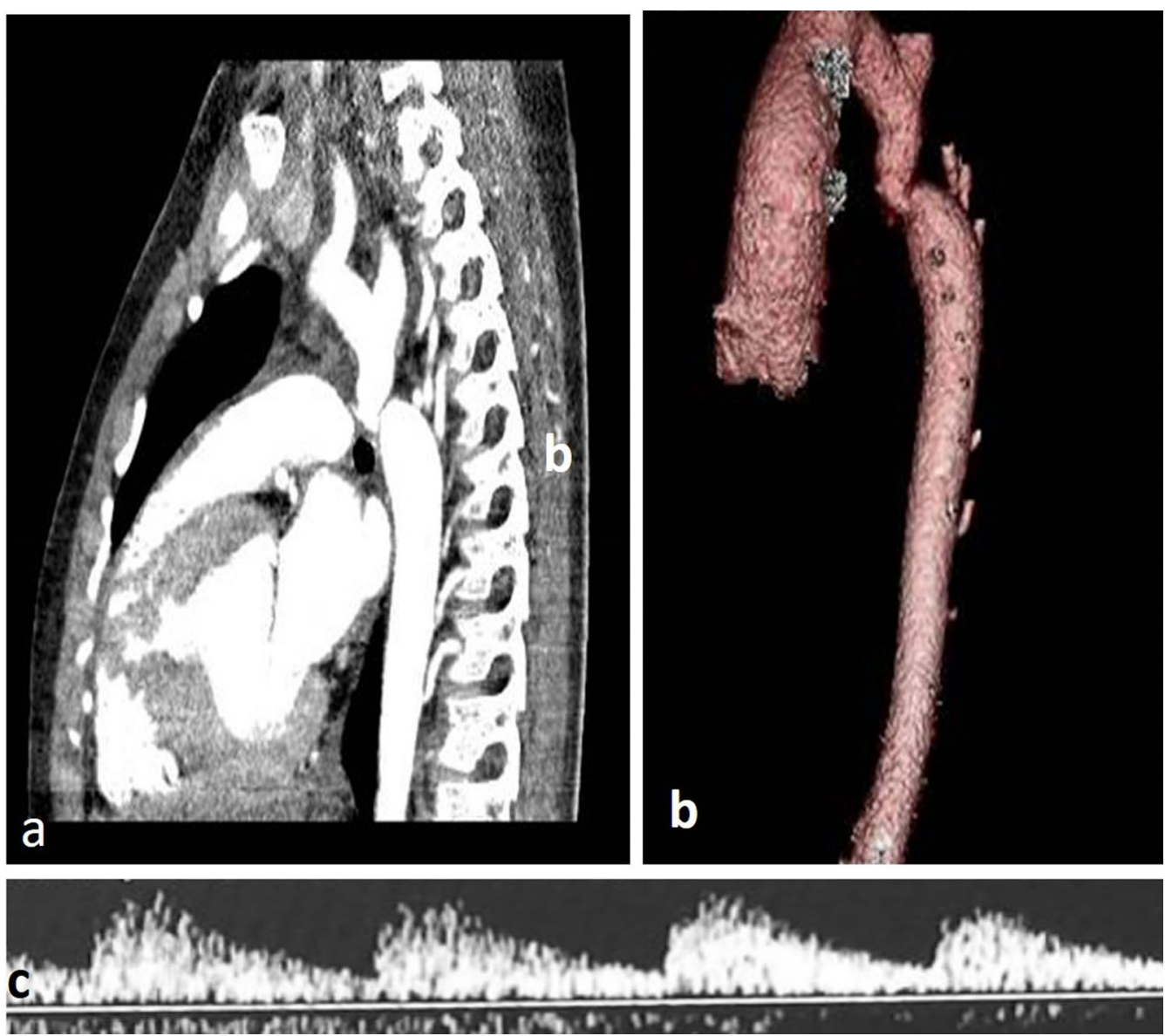

Fig. 19 9-year-old boy with drug resistant renovascular hypertension. a, b sagittal reconstruction and 3D format of CT angiography confirms the presence of coarctation of the aorta. c Renal Doppler ultrasound reveals tardus parvus pattern in both kidneys

sensitive in detection of vascular abnormalities of the aorta and intrarenal arteries [35].

\section{Conclusions}

Children from all ages experience different urologic problems. Imaging investigations should be tailored according to the clinical scenario in a stepwise approach aiming for optimum patients' care.

\section{Abbreviations}

DMSA: Dimercaptosuccinic acid; ESUR: European society of uroradiology; MCUG: Micturating cystourethrography; pDRF: Patlak differential renal function; UGS: Urogenital sinus; UTD: Urinary tract dilatation; UTI: Urinary tract infection; VDRF: Volumetric differential renal function.

\section{Supplementary Information}

The online version contains supplementary material available at https://doi. org/10.1186/s43055-021-00584-0.

Additional file 1. Transverse ultrasound showing ureterocele at the posterior aspect of the urinary bladder

Additional file 2. Dynamic post-contrast MRU of case of left PUJ obstruction. The study reveals delayed cortical enhancement on the left with delayed visualization of the left ureter.

\section{Acknowledgements}

Part of this work was presented at ECR 2020 as an electronic poster (educational exhibit). https://doi.org/10.26044/ecr2020/C-11523.

\section{Authors' contributions}

All authors contributed to the article conception and design. Material preparation and data collection were performed by all authors. The first draft of the 
manuscript was written by SAM. All authors read and approved the final manuscript.

\section{Funding}

None.

\section{Availability of data and materials}

All data support the published claims and comply with field standards.

\section{Declarations}

\section{Ethics approval and consent to participate}

This is an educational review article and ethical approval was waived; consent to participate was not applicable.

\section{Consent for publication}

Being an educational review, consent for publication was not required (not applicable).

\section{Competing interests}

The authors declare that they have no conflict of interest.

\section{Author details}

1 Department of Radiodiagnosis, Faculty of Medicine, Ain Shams Universuty, Cairo, Egypt. ${ }^{2}$ Department of Pediatric Surgery, Faculty of Medicine, Ain Shams Universuty, Cairo, Egypt.

Received: 14 June 2021 Accepted: 8 August 2021

Published online: 16 August 2021

\section{References}

1. Arthurs OJ, van Rijn RR, Granata C, Porto L, Hirsch FW, Rosendahl K (2020) European Society of Paediatric Radiology 2019 strategic research agenda: improving imaging for tomorrow's children. Pediatr Radiol 49(8):983-989

2. Riccabona M, Avni FE, Blickman JG, Dacher JN, Darge K, Lobo ML, Willi U (2009) Imaging recommendations in paediatric uroradiology. Minutes of the ESPR uroradiology task force session on childhood obstructive uropathy, high-grade fetal hydronephrosis, childhood haematuria, and urolithiasis in childhood. ESPR Annual Congress, Edinburgh, UK, June 2008. Pediatr Radiol 39(8):891-898

3. Riccabona M, Avni FE, Dacher JN, Damasio MB, Darge K, Lobo ML, OrdingMüller LS, Papadopoulou F, Willi U (2010) ESPR uroradiology task force and ESUR paediatric working group. ESPR uroradiology task force and ESUR paediatric working group: imaging and procedural recommendations in paediatric uroradiology, part III. Minutes of the ESPR uroradiology task force minisymposium on intravenous urography, uro-CT and MRurography in childhood. Pediatr Radiol 40(7):1315-20. Erratum in: Pediatr Radiol (2011) 41(5):678. Papadopolou, Frederika [corrected to Papadopoulou, Frederika]

4. Riccabona M, Lobo ML, Papadopoulou F, Avni FE, Blickman JG, Dacher JN, Damasio B, Darge K, Ording-Müller LS, Vivier PH, Willi U (2011) ESPR uroradiology task force and ESUR paediatric working group: imaging recommendations in paediatric uroradiology, part IV: Minutes of the ESPR uroradiology task force mini-symposium on imaging in childhood renal hypertension and imaging of renal trauma in children. Pediatr Radiol 41(7):939-944

5. Riccabona M, Avni FE, Damasio MB, Ording-Müller LS, Blickman JG, Darge K, Lobo ML, Papadopoulou F, Vivier PH, Willi U (2012) ESPR Uroradiology Task Force and ESUR Paediatric Working Group-Imaging recommendations in paediatric uroradiology, part V: childhood cystic kidney disease, childhood renal transplantation and contrast-enhanced ultrasonography in children. Pediatr Radiol 42(10):1275-1283

6. Riccabona M, Lobo ML, Willi U, Avni F, Damasio B, Ording-Mueller LS, Blickman J, Darge K, Papadopoulou F, Vivier PH (2014) ESPR uroradiology task force and ESUR Paediatric Work Group_-Imaging recommendations in paediatric uroradiology, part Vl: childhood renal biopsy and imaging of neonatal and infant genital tract. Minutes from the task force session at the annual ESPR Meeting 2012 in Athens on childhood renal biopsy and imaging neonatal genitalia. Pediatr Radiol 44(4):496-502

7. Riccabona M, Vivier PH, Ntoulia A, Darge K, Avni F, Papadopoulou F, Damasio B, Ording-Muller LS, Blickman J, Lobo ML, Willi U, Uroradiology Task Force ESPR (2014) ESPR uroradiology task force imaging recommendations in paediatric uroradiology, part VII: standardised terminology, impact of existing recommendations, and update on contrastenhanced ultrasound of the paediatric urogenital tract. Pediatr Radiol 44(11):1478-1484

8. Riccabona M, Lobo ML, Ording-Muller LS, Thomas Augdal A, Fred Avni E, Blickman J, Bruno C, Damasio B, Darge K, Ntoulia A, Papadopoulou F, Vivier PH (2017) European Society of Paediatric Radiology abdominal imaging task force recommendations in paediatric uroradiology, part IX: imaging in anorectal and cloacal malformation, imaging in childhood ovarian torsion, and efforts in standardising paediatric uroradiology terminology. Pediatr Radiol 47(10):1369-1380

9. Nguyen HT, Benson CB, Bromley B, Campbell JB, Chow J, Coleman B, Cooper C, Crino J, Darge K, Herndon CD, Odibo AO, Somers MJ, Stein DR (2014) Multidisciplinary consensus on the classification of prenatal and postnatal urinary tract dilation (UTD classification system). J Pediatr Urol 10(6):982-998

10. Cerrolaza JJ, Peters CA, Martin AD, Myers E, Safdar N, Linguraru MG (2016) Quantitative ultrasound for measuring obstructive severity in children with hydronephrosis. J Urol 195(4, pt 1):1093-1099

11 Riccabona M (2011) Potential role of 3DUS in infants and children. Pediatr Radiol 41(suppl 1):S228-S237

12. Riccabona M (2006) Modern pediatric ultrasound: potential applications and clinical significance. A review. Clin Imaging 30(2):77-86

13. American College of Radiology (2019) ACR-SPR practice parameter for the performance of fluoroscopic and sonographic voiding cystourethrography in children. https://www.acr.org/-/media/ACR/Files/Pract ice-Parameters/VoidingCysto.pdf. Accessed 20 April 2021

14. McArthur C, Baxter GM (2012) Current, and potential renal applications of contrast enhanced ultrasound. Clin Radiol 67(9):909-922

15. Mendichovszky I, Solar BT, Smeulders N, Easty M, Biassoni L (2017) Nuclear medicine in pediatric nephro-urology: an overview. Semin Nucl Med 47(3):204-228

16. Dickerson EC, Dillman JR, Smith EA, DiPietro MA, Lebowitz RL, Darge K (2015) Pediatric MR urography: indications, techniques, and approach to review. Radiographics 35(4):1208-1230

17. Chalouhi GE, Millischer AÉ, Mahallati H, Siauve N, Melbourne A, Grevent D, Vinit N, Heidet L, Aigrain Y, Ville Y, Blanc T, Salomon LJ (2020) The use of fetal MRI for renal and urogenital tract anomalies. Prenat Diagn 40(1):100-109

18. Jones RA, Grattan-Smith JD, Little S (2011) Pediatric magnetic resonance urography. J Magn Reson Imaging 33(3):510-526

19. Grattan-Smith JD, Jones RA (2008) MR urography in children. In: Fotter $R$ (ed) Pediatric uroradiology. Springer, Berlin, pp 17-36

20. Okarska-Napierała M, Wasilewska A, Kuchar E (2017) Urinary tract infection in children: diagnosis, treatment, imaging-comparison of current guidelines. J Pediatr Urol 13(6):567-573

21. Nevéus T, Fonseca E, Franco I, Kawauchi A, Kovacevic L, NieuwhofLeppink A, Raes A, Tekgül S, Yang SS, Rittig S (2020) Management and treatment of nocturnal enuresis - an updated standardization document from the International Children's Continence Society. J Pediatr Urol 16(1):10-19

22 Joensson IM, Siggaard C, Rittig S, Hagstroem S, Djurhuus JC (2008) Transabdominal ultrasound of rectum as a diagnostic tool in childhood constipation. J Urol 179(5):1997-2002

23. Servaes S, Khanna G, Naranjo A, Geller Jl, Ehrlich PF, Gow KW, Perlman EJ, Dome JS, Gratias E, Mullen EA (2015) Comparison of diagnostic performance of CT and MRI for abdominal staging of pediatric renal tumors: a report from the Children's Oncology Group. Pediatr Radiol 45(2):166-172

24. Chepelev L, Wake N, Ryan J, Althobaity W, Gupta A, Arribas E, Santiago L, Ballard DH, Wang KC, Weadock W, lonita CN, Mitsouras D, Morris J, Matsumoto J, Christensen A, Liacouras P, Rybicki FJ, Sheikh A (2018) RSNA Special Interest Group for 3D Printing. Radiological Society of North America (RSNA) 3D printing Special Interest Group (SIG): guidelines for medical 3D printing and appropriateness for clinical scenarios. 3D Print Med 4(1):11 
25. Laméris W, van Randen A, van Es HW, van Heesewijk JP, van Ramshorst B, Bouma WH, ten Hove W, van Leeuwen MS, van Keulen EM, Dijkgraaf MG, Bossuyt PM, Boermeester MA, Stoker J, OPTIMA study group (2009) Imaging strategies for detection of urgent conditions in patients with acute abdominal pain: diagnostic accuracy study. BMJ 338:b2431

26. Marra G, Taroni F, Berrettini A, Montanari E, Manzoni G, Montini G (2019) Pediatric nephrolithiasis: a systematic approach from diagnosis to treatment. J Nephrol 32(2):199-210

27. Massengill SF (2008) Hematuria. Pediatr Rev 29(10):342-348

28 Kolon TF, Herndon CD, Baker LA et al (2014) Evaluation and treatment of cryptorchidism: AUA guideline. J Urol 192(2):337-345

29. Radmayr C, Dogan HS, Hoebeke P et al (2016) Management of undescended testes: European Association of Urology/European Society for Paediatric Urology Guidelines. J Pediatr Urol 12(6):335-343

30. Tasian GE, Copp HL, Baskin LS (2011) Diagnostic imaging in cryptorchidism: utility, indications, and effectiveness. J Pediatr Surg 46(12):2406-2413

31. AbouZeid AA, Mohammad SA (2020) Transformation of the female genitalia in congenital adrenal hyperplasia: MRI study. J Pediatr Surg. 55(5):977-984
32. Mohammad SA, Abouzeid AA (2013) MRI of persistent cloaca: can it substitute conventional imaging? Eur J Radiol 82(2):241-251

33. AbouZeid AA, Mohammad SA (2019) The cloacal anomalies: anatomical insights through a complex spectrum. J Pediatr Surg 54(10):2004-2011

34. Castelli PK, Dillman JR, Kershaw DB, Khalatbari S, Stanley JC, Smith EA (2014) Renal sonography with Doppler for detecting suspected pediatric renin-mediated hypertension - is it adequate? Pediatr Radiol 44(1):42-49

35. Chhadia S, Cohn RA, Vural G, Donaldson JS (2013) Renal Doppler evaluation in the child with hypertension: a reasonable screening discriminator? Pediatr Radiol 43(12):1549-1556

\section{Publisher's Note}

Springer Nature remains neutral with regard to jurisdictional claims in published maps and institutional affiliations.

\section{Submit your manuscript to a SpringerOpen ${ }^{\circ}$ journal and benefit from:}

- Convenient online submission

- Rigorous peer review

- Open access: articles freely available online

- High visibility within the field

- Retaining the copyright to your article

Submit your next manuscript at $\gg$ springeropen.com 